\title{
Base Monolithic Fuel: Research, Development, and Qualification Plan
}

K. Daum, Carla Miller, Brian Durtschi

December 2014

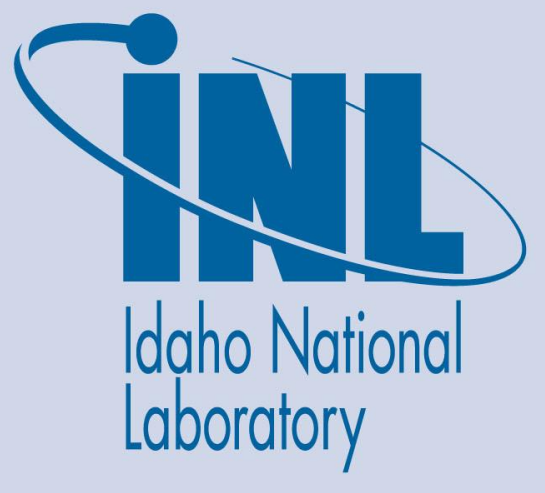

The INL is a U.S. Department of Energy National Laboratory operated by Battelle Energy Alliance 


\section{DISCLAIMER}

This information was prepared as an account of work sponsored by an agency of the U.S. Government. Neither the U.S. Government nor any agency thereof, nor any of their employees, makes any warranty, expressed or implied, or assumes any legal liability or responsibility for the accuracy, completeness, or usefulness, of any information, apparatus, product, or process disclosed, or represents that its use would not infringe privately owned rights. References herein to any specific commercial product, process, or service by trade name, trade mark, manufacturer, or otherwise, does not necessarily constitute or imply its endorsement, recommendation, or favoring by the U.S. Government or any agency thereof. The views and opinions of authors expressed herein do not necessarily state or reflect those of the U.S. Government or any agency thereof. 
INL/EXT-13-30238

Revision 0

\title{
Base Monolithic Fuel: Research, Development, and Qualification Plan
}

\author{
K. Daum, Carla Miller, Brian Durtschi
}

December 2014

Idaho National Laboratory Idaho Falls, Idaho 83415

http://www.inl.gov

Prepared for the

U.S. Department of Energy

National Nuclear Security Administration

Under DOE Idaho Operations Office

Contract DE-AC07-05ID14517 
INTENTIONALLY BLANK 


\begin{abstract}
The Office of Global Threat Reduction Initiative within the U.S. DOE/National Nuclear Security Administration is working to convert research reactors globally from highly enriched uranium (HEU) fuel to low-enriched uranium (LEU) fuel. Of the 200 candidate HEU research reactors, over 80 reactors have been converted using LEU fuel. Additional reactor conversions using this fuel are currently underway. However, there is a set of high performance research reactors that require a new high density LEU fuel for conversion, including six U.S. high performance research reactors (USHPRRs).

This research, development, and qualification plan provides the general approach for the USHPRR team to move the selected U-Mo fuel design through generic qualification to licensing and use. The plan includes the currently available information on the requirements for qualification and use of the fuel. It also describes the methods by which data will be collected to show that these requirements have been met.
\end{abstract}


INTENTIONALLY BLANK 


\section{CONTENTS}

ABSTRACT

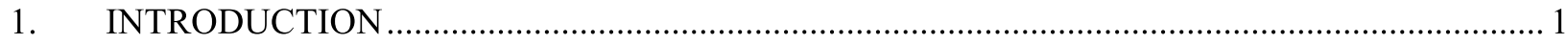

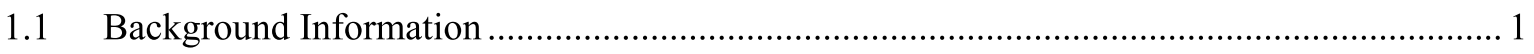

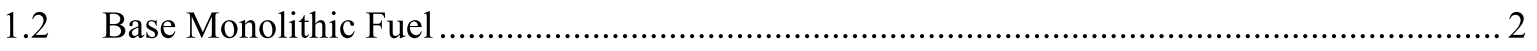

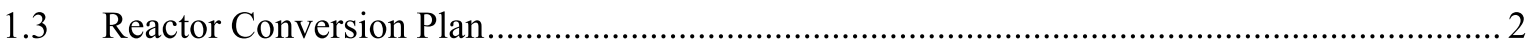

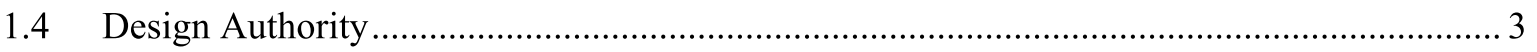

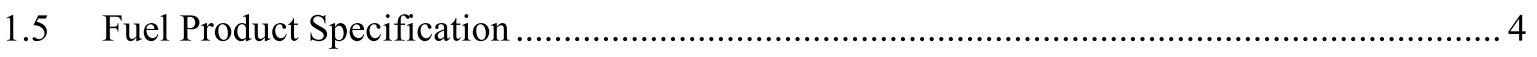

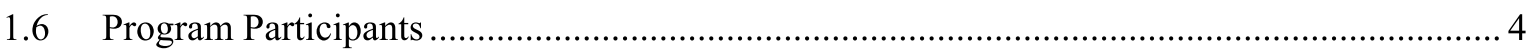

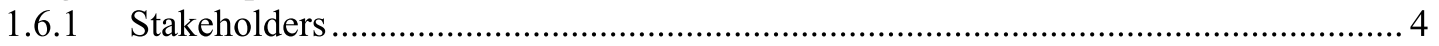

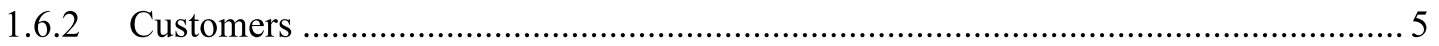

1.7 Previous Qualification Efforts and Historical Precedence …......................................... 5

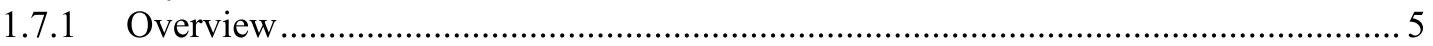

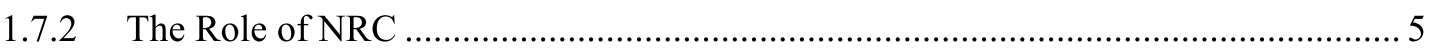

1.7.3 International Atomic Energy Agency Good Practices ......................................... 7

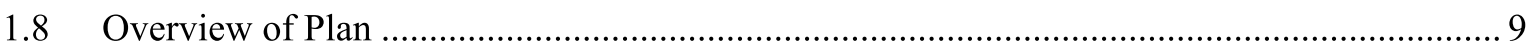

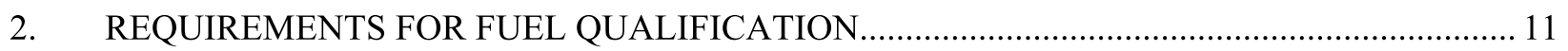

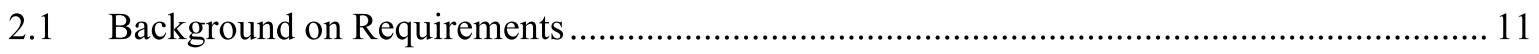

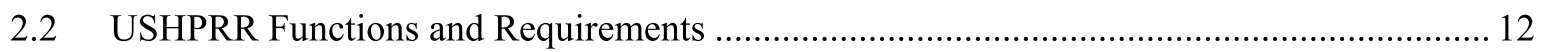

2.2.1 Meeting Requirements for Base Fuel Qualification............................................ 13

2.2.2 Requirements for Post-Qualification Fuel Acceptance.......................................... 19

3. APPROACH TO FUEL DEVELOPMENT AND QUALIFICATION ......................................... 21

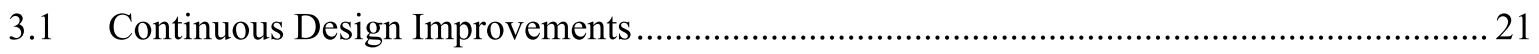

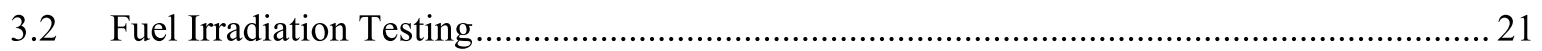

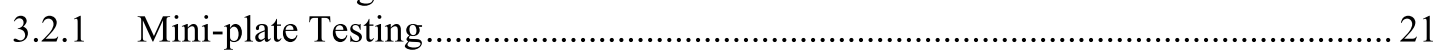

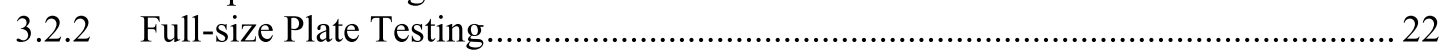

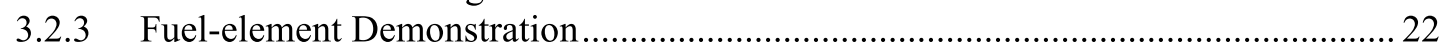

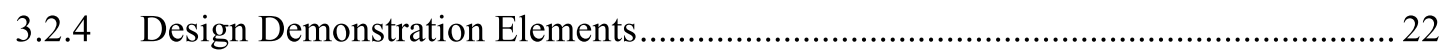

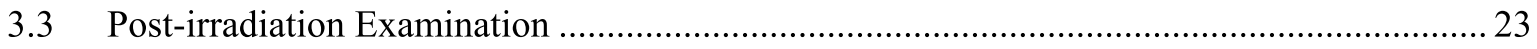

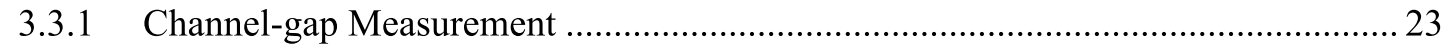

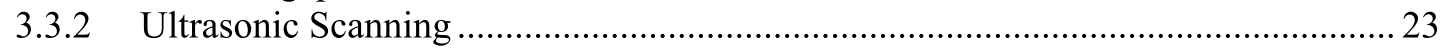

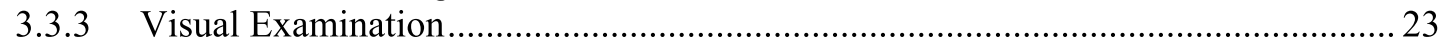

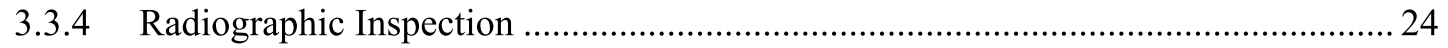

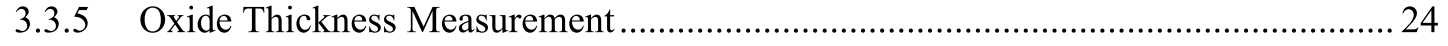

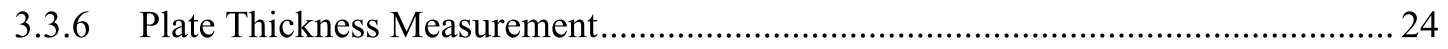

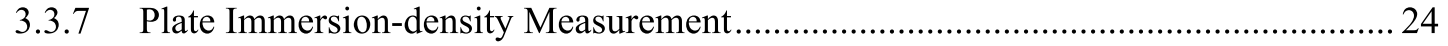

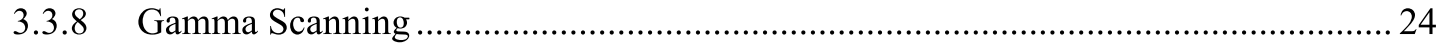

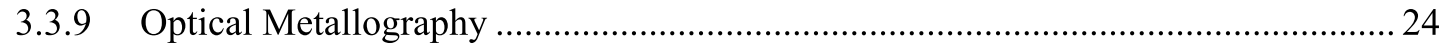

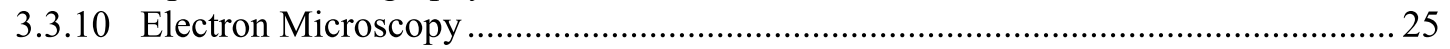

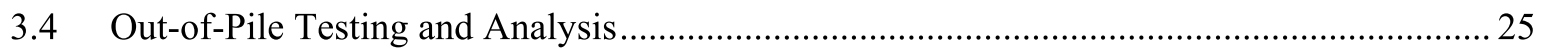

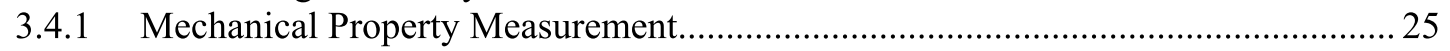




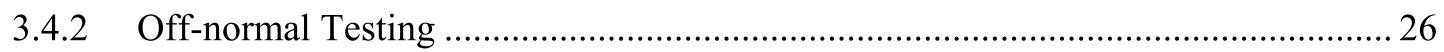

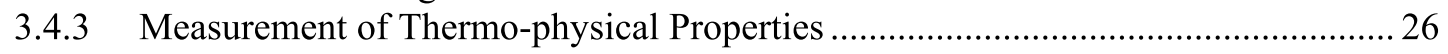

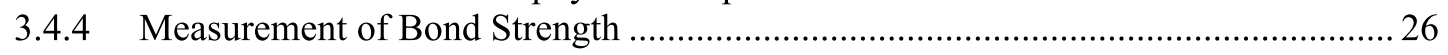

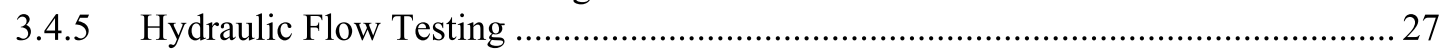

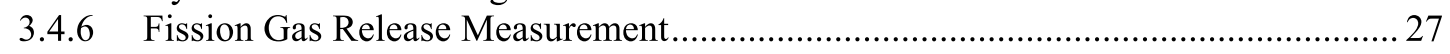

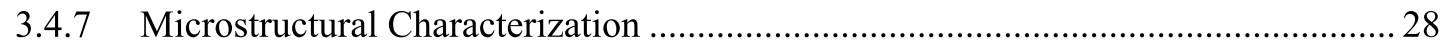

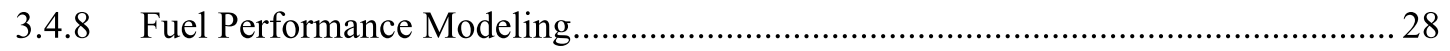

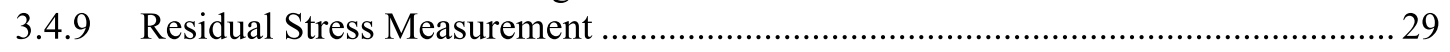

4. FUEL QUALIFICATION AND DEMONSTRATION TESTING ............................................. 30

4.1 Basic Objectives for Testing to Support Fuel Qualification for NRC Reactors ................... 30

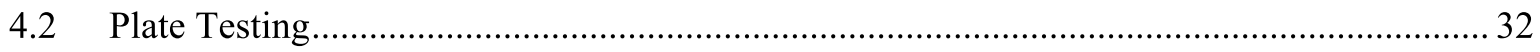

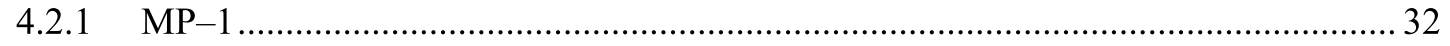

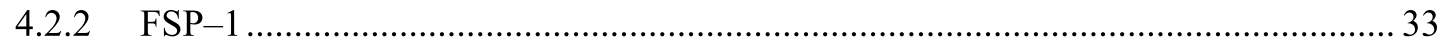

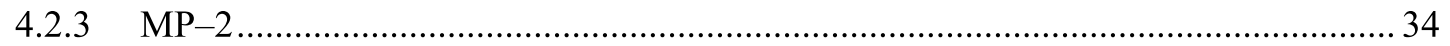

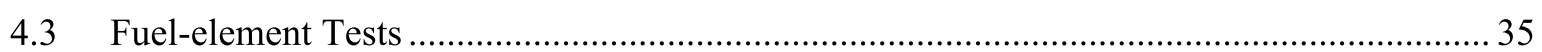

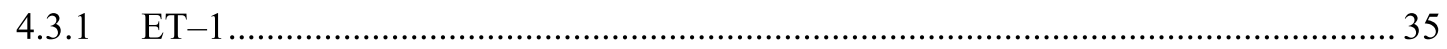

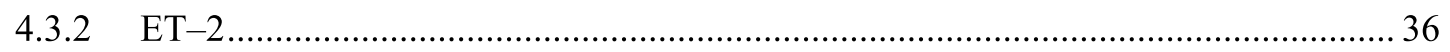

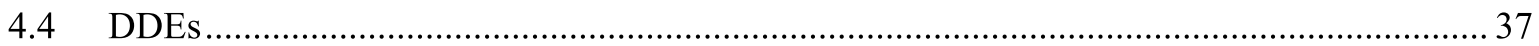

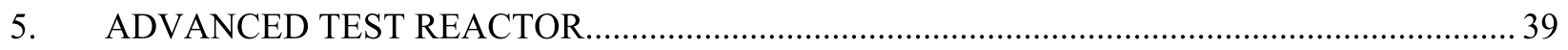

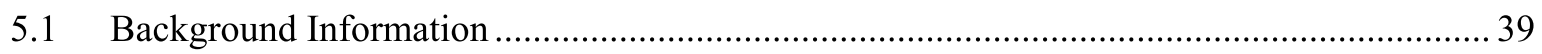

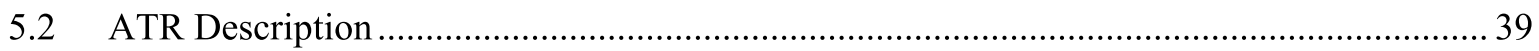

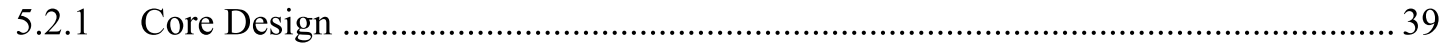

5.3 ATR Reactor Conversion Schedule .................................................................................. 41

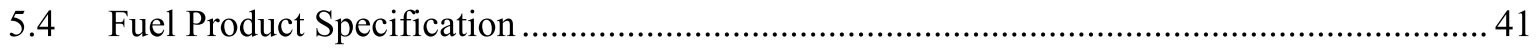

5.5 Previous Qualification Efforts and Historical Precedence ................................................... 41

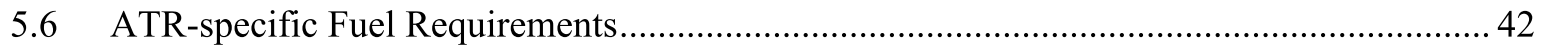

5.7 Overview of ATR Fuel Qualification Plan ....................................................................... 44

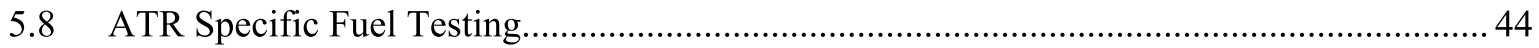

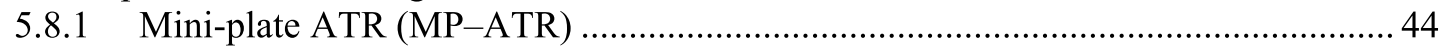

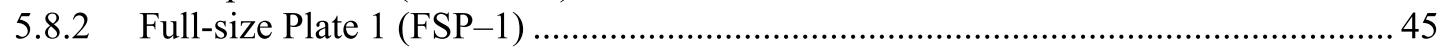

5.8.3 Full-size Plate ATR High Power Test (FSP-ATR-High) ......................................... 45

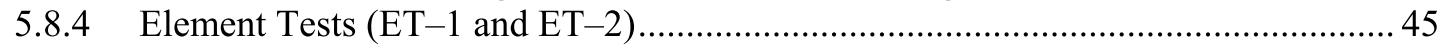

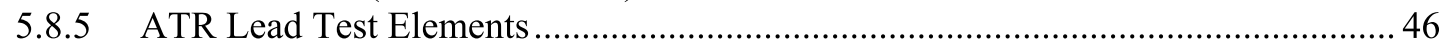

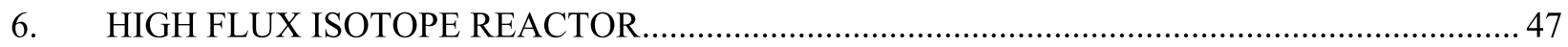

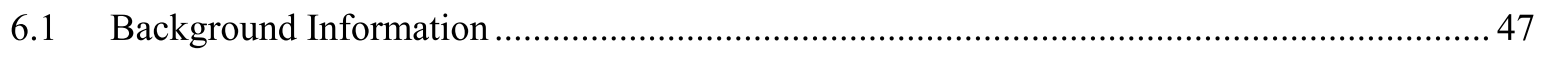

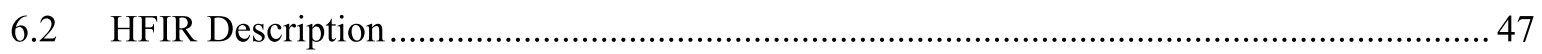

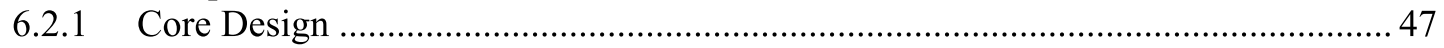

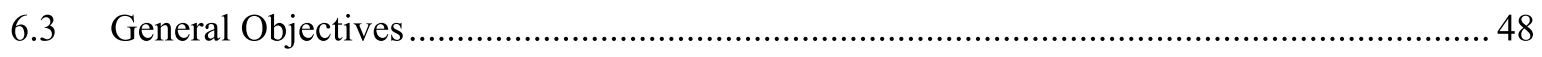

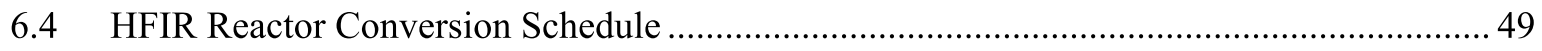

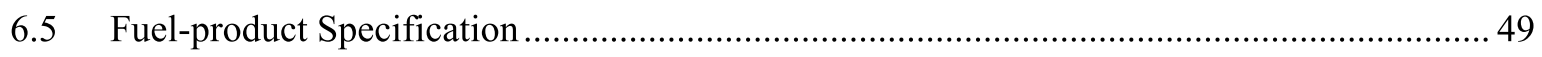

6.6 Previous Qualification Efforts and Historical Precedence ............................................... 49

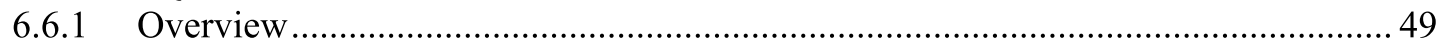




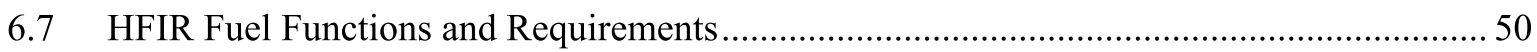

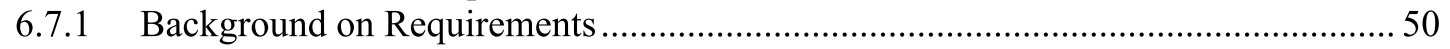

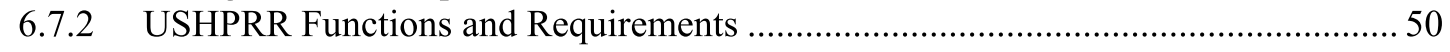

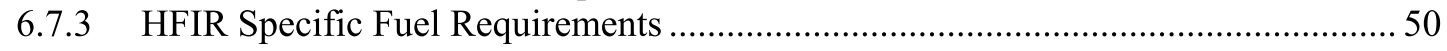

6.7.4 Overview of HFIR Fuel Qualification Plan ...................................................... 51

6.8 HFIR-specific Testing to Support Fuel Qualification and Demonstration..............................53

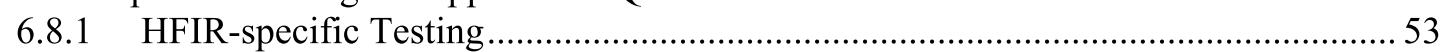

6.8.2 Requirements for Post-Qualification Fuel Acceptance........................................ 56

7. DATA QUALITY PLANNING AND QUALITY ASSURANCE ............................................. 57

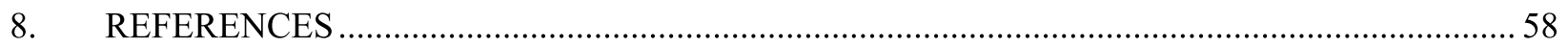

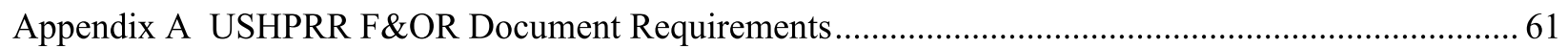

\section{FIGURES}

Figure 1. Schematic diagram of the base monolithic fuel.................................................................. 2

Figure 2. Flow of requirements and information for fuel qualification and licensing. ............................. 10

Figure 3. Schematic flowchart showing steps for USHPRR fuel qualification. ........................................ 11

Figure 4. Structure of USHPRR functional requirements..................................................................... 13

Figure 5. The June 2014 roadmap for the schedule of tests that will collect the necessary data for

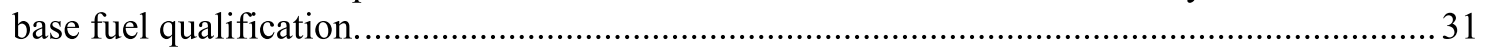

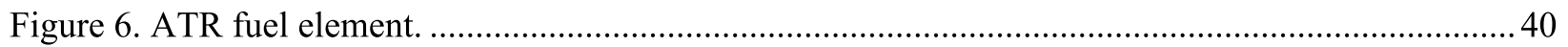

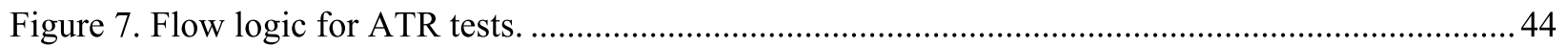

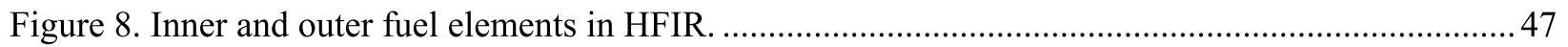

Figure 9. Flow of requirements for HFIR fuel qualification and reactor conversion. ..............................52

Figure 10. Schematic flowchart showing steps for HFIR fuel qualification...........................................54

\section{TABLES}

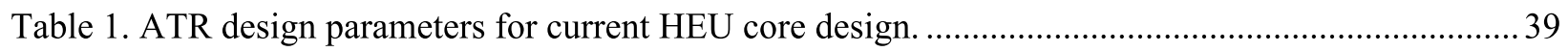

Table 2. Comparison of fuel specifications for HEU and LEU in the HFIR core. .................................... 48 
INTENTIONALLY BLANK 


\section{ACRONYMS}

ATR

Advanced Test Reactor (Idaho National Laboratory)

ATRC

ATR-Criticality Facility (Idaho National Laboratory)

DA

Design Authority

DDE

Design Demonstration Element

DOE

Department of Energy

DOE-ID

Department of Energy, Idaho Field Office

DOE-NE

Department of Energy, Office of Nuclear Engineering

DOE-SC

Department of Energy, Office of Science

FA

fuel assembly

FD

Fuel Development

FE

fuel element

FFC

Fuel Fabrication Capabilities

FSI

Fluid-structure interaction

GTRI Global Threat Reduction Initiative

HEU

highly enriched uranium

HFIR

High Flux Isotope Reactor (Oak Ridge National Laboratory)

IAEA

International Atomic Energy Agency

INL

Idaho National Laboratory

LEU

low-enriched uranium

MITR

Massachusetts Institute of Technology Reactor

MURR University of Missouri Research Reactor

NBSR National Bureau of Standards Reactor

NNSA National Nuclear Security Administration

NRC Nuclear Regulatory Commission

PIE post-irradiation examination

QA Quality Assurance

RC Reactor Conversion

RERTR Reduced Enrichment for Research and Test Reactors

SAR Safety Analysis Report 
SCK-CEN Studeicentrum voor Kernenergie - Centre d'Etude de l'Energie Nucléaire

TRIGA Training, Research, Isotopes, General Atomic

USHPRR United States high-performance research reactor 


\section{Base Monolithic Fuel: Research, Development, and Qualification Plan \\ 1. INTRODUCTION}

\subsection{Background Information}

The Office of Global Threat Reduction Initiative (GTRI) within the U.S. DOE/National Nuclear Security Administration (NNSA) is working to convert research reactors globally from highly enriched uranium (HEU) fuel to low-enriched uranium (LEU) fuel. Of the 200 candidate research reactors, over 80 have been converted using LEU fuel developed in the 1980s. Additional reactor conversions using this fuel are currently underway. However, there is a small set of high-performance research reactors that require a new high-density LEU fuel for conversion, including six U.S. high-performance research reactors (USHPRRs). Combined, the high-performance reactors in the U.S., Russia, and Europe are responsible for $650-750 \mathrm{~kg}$ of HEU use annually. ${ }^{1}$

The USHPRR Conversion Program is developing replacement LEU fuels and associated fuelfabrication capabilities for the remaining USHPRRs that cannot convert with existing LEU fuels. These remaining USHPRRs include nuclear research reactors at:

- The Massachusetts Institute of Technology (Massachusetts Institute of Technology Reactor [MITR])

- The University of Missouri (Missouri University Research Reactor [MURR])

- The National Institute of Standards and Technology (National Bureau of Standards Reactor [NBSR])

- Oak Ridge National Laboratory (High Flux Isotope Reactor [HFIR])

- Idaho National Laboratory (Advanced Test Reactor [ATR] and ATR-Critical Facility [ATRC]).

This document updates the previous 2011 plan $^{2}$ based on a new program roadmap developed in 2012. The body of this document is focused on defining the activities required for qualifying replacement LEU fuel to allow reactor conversions to proceed for the four high-performance research reactors that will operate using the 'base' LEU fuel design (see Subsection 1.2): MITR, MURR, NBSR, and ATR.

Section 6 is included to address fuel development for HFIR, which uses a more complex fuel system that requires graded fuel plates and a burnable absorber.

To be successful, the USHPRR Conversion Program must develop LEU fuels that are:

- Qualified: Fuel that has been successfully irradiation tested; the integrity and performance of the fuel has been demonstrated through analysis and testing and shown to meet requirements for qualification. Successful fuel, as demonstrated by testing, analysis, and regulatory approval is, therefore, licensable in individual reactors.

- Commercially available: Fuel that is available from a commercial manufacturer.

- Suitable:

- Fuel satisfies the safety criteria and safety margins

- Fuel satisfies geometric criteria for LEU conversion of a specific reactor

- Fuel service lifetime is comparable to current HEU fuel (e.g., the number of fuel elements used per year is the same as or less than with HEU fuel).

- Fuel provides similar operational and experimental performance parameters to those provided by the HEU fuel currently used and does not significantly compromise the reactor's current reactivity and operations

- Fuel fabrication process does not adversely affect fuel performance or qualification 
- Fuel fabrication process is optimized to improve cost basis, production rate, and the sustainability of resources.

- Acceptable:

- Fuel that the reactor operator and regulator must agree to accept for conversion based on the above objectives.

\subsection{Base Monolithic Fuel}

The selected design for the generic fuel system is referred to as "base monolithic fuel" or simply "base fuel", and comprises a uranium-10 wt\% molybdenum alloy (U-10Mo) in the form of a monolithic foil, with thin zirconium (Zr) interlayers, clad in 6061 aluminum (Al), as shown schematically in Figure $1 .^{3}$

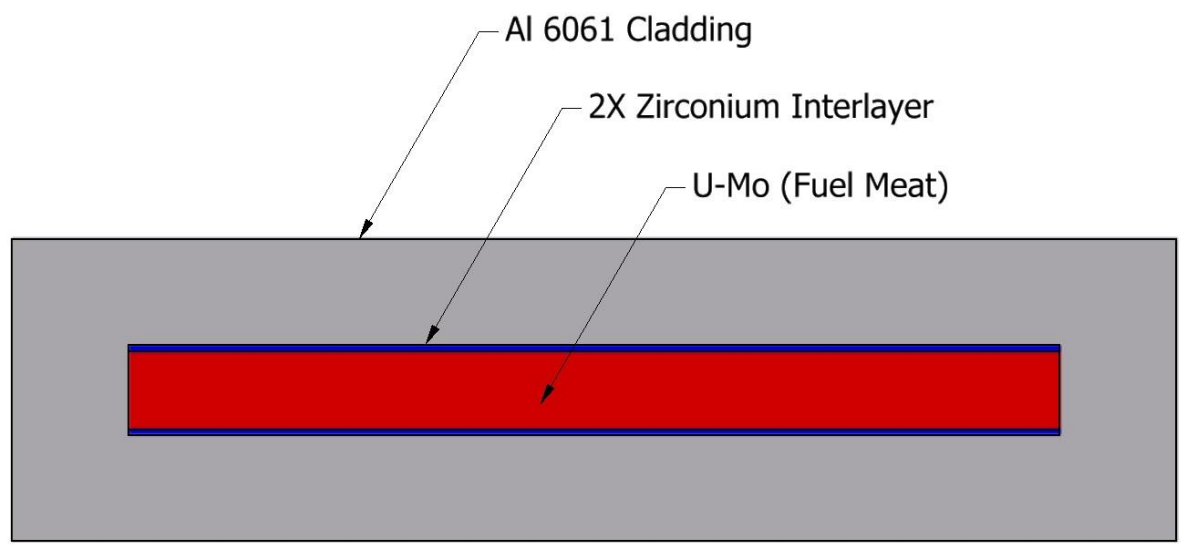

Figure 1. Schematic diagram of the base monolithic fuel.

During the fuel development and qualification process, the fuel-system design matures through testing, analysis, and manufacturing process development. The selection of specific design features and oversight of the manufacturing development activities are the responsibility of the Design Authority (DA), as explained below, through which specifications and manufacturing plans are configuration controlled and continually updated, as needed. A summary of the logic behind fuel design decisions is maintained in the current revision of the U-Mo monolithic fuel design selection report, ${ }^{3}$ which is updated as necessary to reflect new information available from testing, analysis, or changes to performance requirements.

In general, testing is carried out on the individual fuel-system components and after fabrication into fuel plates, which may be tested individually, in irradiation test assemblies, or in fuel elements designed to meet the specifications of individual reactors.

\subsection{Reactor Conversion Plan}

Conversion studies performed for the three high-performance research reactors that are regulated by the NRC and that operate at moderate power density (i.e., MITR, MURR, and NBSR) have shown that LEU conversion is viable using the selected base fuel design., ${ }^{4,6}$

A recently concluded analysis of the $\mathrm{ATR}^{7}$ indicates the technical viability of conversion using the base fuel design, although the ATR reactor operates at much higher fuel power densities than MITR, MURR, and NBSR. ${ }^{7}$ ATR operates under the Department of Energy, Office of Nuclear Engineering (DOE-NE). 
A more complicated monolithic fuel design (referred to as "complex fuel") involving fuel plates containing burnable absorbers and/or shaped fuel-meat geometries may be required for LEU conversion of the High Flux Isotope Reactor (HFIR) at Oak Ridge National Laboratory. ${ }^{8}$ Complex fuel poses additional challenges for fabrication; however; it is anticipated to be a variant of the base fuel, and builds upon base fuel qualification. For example, a fuel element that incorporates burnable absorbers outside of the fuel zone or in components outside of the fuel plate may be suitable for conversion of HFIR.

The current priority is qualification and subsequent demonstration of the base fuel for the NRC reactors listed above, followed by ATR and then HFIR. ATR requires testing at higher power densities than the NRC regulated reactors. Because HFIR requires the most complex fuel design, development and qualification builds on fuel qualification of the NRC-regulated reactors and the ATR. Fuel qualification for HFIR is addressed in Section 6 of this document.

The GTRI-USHPRR Conversion Program is organized according to three pillars that work together to achieve the final, qualified fuel product: Fuel Development (FD), Fuel Fabrication Capabilities (FFC), and Reactor Conversion (RC). ${ }^{9}$ A fourth pillar (Convert Integration) has been added to integrate crosscutting activities across all pillars.

The FD Pillar is responsible for the development and qualification of a U-Mo alloy fuel that will permit USHPRR conversions to LEU. Major fuel-development activities focus on demonstrating, through testing and analysis, that the new fuel meets the operational safety, dimensional-stability, thermal stability, and other requirements of the respective regulatory agency (i.e., NRC, DOE-NE or DOE-SC).

The FD pillar interfaces with the FFC and RC pillars to ensure that fuels developed by the GTRI USHPRR Conversion Program are qualified, commercially available, and suitable, according to the above-stated success criteria.

The primary deliverable of this fuel qualification effort is a qualified base fuel design. This involves:

- Executing a test program that successfully demonstrates that the fuel design can be licensed for use in the USHPRRs

- Submitting a Base Fuel Qualification Report to the NRC for generic approval of the fuel

- Conducting reactor-specific fuel-element testing to support the safety basis for the conversion of each reactor.

The FD pillar also addresses requests for reactor-physics benchmarking data in conjunction with fuel testing in response to individual requests made through the RC pillar.

\subsection{Design Authority}

A DA has been established for the GTRI/USHPRR Conversion Program, the mission of which is described in its charter:
A key input to the fuel development is the specifications for the fuel product that needs to be fabricated. The fuel product specification development, a focus of the fuel development and qualification activities, will be led by a GTRI/USHPRR designated Design Authority (DA). The Fuel Product Specification DA will lead the fuel product specification design team consisting of representatives from key stakeholders to ensure integration with the key parts of the GTRI/USHPRR program including the Fuel Development (FD), the Fuel Fabrication Capability (FFC) and Reactor Conversion (RC) pillars. ${ }^{10}$ 
The DA will address ongoing issues and decisions associated with the technical integration of the Fuel Product Specification. The team will also serve as a forum for exchange and review of technical information relevant to decisions affecting the fuel system. The chairperson will facilitate all meetings, be the clearinghouse for comment resolution, and report directly to the FD pillar lead. The DA will also maintain a Functional and Operational Requirements (F\&OR) document with input from the USHPRRs, FFC, RC, and FD documenting the testing envelope requirements for irradiation tests. ${ }^{11}$

The DA fuel-product specification is a generic specification that provides bounding limits for all the USHPRRs. The fuel-product specification is designed to guide the fabrication of test specimens for each specific qualification test. Each irradiation test, however, requires its own detailed test fuel specification that includes fuel plate dimensions.

After GTRI/USHPRR research, development and qualification efforts culminate in successful base fuel qualification, the DA functional responsibility, and ownership of the then-current Fuel Product Specification, will transition to each USHPRR, leading to reactor-specific specifications suitable for licensing and procurement of commercial fuel.

\subsection{Fuel Product Specification}

The Fuel Product Specification defines target values and tolerances (or acceptable ranges) for those attributes of the fuel system that are critical to meeting fuel-performance and reactor-safety requirements. Attributes and target values are based on technical evaluations conducted with input from the USHPRRs, $\mathrm{FD}, \mathrm{RC}$ and FFC, based on information from existing HEU fuel specifications, earlier fuel development efforts, this plan, and input from the DA.

The initial Fuel Product Specification is intended as a guide to fabricators and end users. It is a generic specification, in that it does not specify dimensional information or other reactor-specific details. Using the specification, FFC will work with the fabricator and other stakeholders to develop commercially viable fabrication processes that meet the specifications. Specific design information for FD fuel-testing campaigns and design demonstration elements (DDEs, previously and in some other documents referred to as design demonstration experiments) are based on the Fuel Product Specification. Using the Fuel Product Specification, RC will work with the reactors to develop fuel-element designs that will be used for reactor conversion. The Fuel Product Specification will be updated on a periodic basis and as new information becomes available to the DA.

\subsection{Program Participants}

\subsubsection{Stakeholders}

The primary stakeholders of the USHPRR Conversion Program are listed below. Definitions and explanations of roles can be found in the FD Project Execution Plan (PEP). ${ }^{12}$

- USHPRR Program Manager

- FFC Pillar

- RC Pillar

- FD Pillar

- USHPRR Convert Program Management Integrator

- DOE-NE

- DOE-SC

- DOE-ID 
- Domestic Research Reactors

- Nuclear Regulatory Commission.

\subsubsection{Customers}

Five US research reactors are both stakeholders and customers in the USHPRR Conversion Program. Three of these reactors are licensed by the NRC:

- Missouri University Research Reactor

- Massachusetts Institute of Technology Reactor

- National Bureau of Standards Reactor.

Two reactors are regulated by DOE:

- Advanced Test Reactor at Idaho National Laboratory (INL) (and ATR Critical Facility at INL), regulated by DOE-NE

- Oak Ridge National Laboratory's High Flux Isotope Reactor, regulated by DOE-SC.

Each reactor is responsible for its Safety Analysis Report (SAR) to the respective regulator. Fuel qualification data are used in the reactor SAR, either directly or through reference to the NUREG that is anticipated to be generated by the regulator to document generic acceptance of the fuel design.

Reactor-specific SAR requirements are also an important input to the global requirements for the development and qualification of the LEU fuel. This information will be compiled by the reactors and communicated to FD through the RC pillar or through information exchanges.

\subsection{Previous Qualification Efforts and Historical Precedence}

\subsubsection{Overview}

Most research reactors use a dispersion of fuel particles in an aluminum matrix, clad in aluminum, manufactured using the roll-bonding process. This system is robust and suitable for operation at very high power density. In order to convert from high enrichment (typically 93wt.\% U-235) to low enrichment (less than $20 \mathrm{wt} . \% \mathrm{U}-235$ ), the total amount of uranium in the fuel (the fuel density) must be increased by at least the ratio of $U-235$ in HEU to that in LEU, i.e., 93/20, with additional uranium required to compensate for parasitic absorption from U-238. LEU research-reactor fuel, therefore, must contain much more uranium in the same volume than highly enriched fuel. Each US research-reactor stakeholder listed above requires a fuel form of higher fuel density than $4.8 \mathrm{gU} / \mathrm{cm}^{3}$, the maximum approved density of the dispersion fuel currently in use. The base-fuel design, described previously, employs a monolithic UMo alloy fuel zone that is able to achieve the target fuel densities. This fuel is manufactured by a different production process.

Although previous LEU fuel qualification efforts were for dispersion fuel, these past efforts serve as a general guide for qualification of monolithic fuel.

\subsubsection{The Role of NRC}

The GTRI/USHPRR Conversion Program will develop and provide the testing and analysis required to qualify a new monolithic form for the reactors regulated by the NRC. The program will provide a comprehensive Base Fuel Qualification Report to the NRC. After resolution of Requests for Additional Information (RAIs), the GTRI/USHPRR Conversion Program anticipates generic acceptance of the base fuel design in the form of a Nuclear Regulatory Guide (NUREG) issued by the NRC.

The NRC has not established a prescriptive requirement for research-reactor fuel qualification; that is, it does not provide a step-by-step plan or set of requirements for fuel acceptance. There have been two qualification efforts for dispersion fuels that provide historical precedence and a general guide for 
qualification of the proposed new monolithic fuel: (1) NUREG-1313, the evaluation of the safety of the previously approved LEU silicide fuel now in use in many research reactors ${ }^{13}$ and (2) NUREG-1282, the evaluation of the safety of the previously approved Training, Research, Isotopes, General Atomic (TRIGA) U-Zr hydride fuel. ${ }^{14}$ Each fuel type is used in several research reactors. Of these reports, NUREG-1313 is most generally applicable because it directly addresses plate-type research-reactor fuel with aluminum cladding. In addition, NUREG-1537 provides information on general guidelines that apply to the licensing of fuel systems by individual reactors. ${ }^{15}$

Generic acceptance of $\mathrm{U}_{3} \mathrm{Si}_{2}$ dispersion fuel was based on the following data contained in NUREG-1313:

- Fuel system description

- Materials properties

- Fuel core porosity

- Heat capacity

- Thermal conductivity

- Compatibility of $\mathrm{U}_{3} \mathrm{Si}_{2}$ and aluminum

- Exothermic energy releases

- Corrosion behavior

- Irradiation behavior

- Swelling

- Blister resistance

- Fission-product release.

Although less applicable, the generic acceptance of the U-Zr hydride was based on the following data contained in NUREG-1282:

- Fuel-system description

- Reactor physics

- Materials properties

- Thermal conductivity

- Heat capacity

- Thermal expansion

- Hydrogen dissociation pressure

- Quench response

- Thermal cycling

- Fuel/cladding compatibility

- Irradiation performance

- Fuel swelling

- Axial growth

- Rod bending

- Hydrogen migration

- Fission product release 
- Pulse heating

- Limiting design basis.

The general licensing guidelines of NUREG-1537, Part 1, Section 4.2.1, states that the following information should be included:

- Chemical composition, enrichment, uranium loading, and important metallurgical features of the Fissile material in the basic fuel unit

- Description of the basic fuel unit, including plates

- Material and structural information such as dimensions, spacing, fabrication methods, compatibility of materials, and specifications with tolerances

- Information on material parameters that could affect fuel integrity, such as melting, softening, or blistering temperatures; corrosion; erosion; and mechanical factors, such as swelling, bending, twisting, compression, and shearing

- Physical properties with significance in regard to safety and fuel integrity that are important for the thermal-hydraulic analyses, such as heat capacity, thermal conductivity, gas evolution or diffusion, occluded or encapsulated void volume, fuel burnup limits, capability to retain fission products, swelling resistance, and buildup of oxides

- If the reactor is designed for pulsing, any special attributes of the fuel that contribute to pulsing safety

- A brief history of the fuel type, with references to the fuel development program, including summaries of performance tests, qualification, and operating history

- Mechanical forces and stresses, hydraulic forces, thermal changes and temperature gradients, internal pressures including that from fission products and gas evolution, and radiation effects including the maximum fission densities and fission rates that the fuel units and elements are designed to accommodate.

\subsubsection{International Atomic Energy Agency Good Practices}

International Atomic Energy Agency (IAEA) Nuclear Energy Series NF-T-5.2, "Good Practices for Qualification of High Density Low Enrichment Uranium Research Reactor Fuels, provides an overview of the fuel qualification process from an international perspective. ${ }^{16}$ The structure of the GTRI-USHPRR Conversion Program reflects these guidelines; its tripartite structure-three pillars-matches IAEA's recommendation that fuel qualification combine efforts of a fuel-development team with those of fuel manufacturers and reactor-conversion experts.

The role of the fuel developer is to provide sufficient information about a new fuel type or a new use for an existing fuel type for a regulatory body to license that fuel type for use under a set of bounding geometric configurations and irradiation conditions.

The role of the fuel manufacturer is to demonstrate to regulatory bodies and customers that fuel elements and fuel assemblies of a particular fuel type can be reliably and consistently manufactured to required specifications.

\subsubsection{IAEA Guidance}

The IAEA guide recommends the following approach to qualification:

- Plan and perform testing which continues to inform design improvements

- Select fuel design for qualification

- Demonstrate that fuel can be fabricated on a production line 
- Qualify the manufacturer of the fuel

- Qualify the production of the fuel.

\subsubsection{IAEA Model}

In the IAEA model, qualification of the fuel is a two-phase process, culminating in licensing:

PHASE 1: FUEL RESEARCH AND DEVELOPMENT
A. Fuel-concept design
B. Fuel-manufacturing development
C. Out-of-pile testing
D. Irradiation testing and post-irradiation examination, and
E. Decision point.

PHASE 2: FUEL PERFORMANCE QUALIFICATION
A. Detailed design
B. Technical specification
C. Prototype manufacturing assessment and development
D. Prototype fuel element (FE) and fuel assembly (FA) manufacturing
E. Qualification test planning
F. Prototype full-size FA irradiation testing, including post-irradiation examinations
G. Fuel qualification report, and
H. Fuel licensing.

\subsubsection{IAEA Design Improvements}

The IAEA suggests the following data to inform design improvements:

- Basic properties of unirradiated fuel

- Fuel-material chemical and phase compositions

- Fuel-material heat capacity

- Fuel-material thermal properties

- Fuel-powder properties (for dispersion fuel)

- Fuel-foil properties (for monolithic fuel)

- Fuel meat and fuel element as-manufactured properties

- Fuel-meat volume and constituent volume

- Fuel-meat (element) heat capacity

- Fuel-meat and cladding thermal conductivities

- Fuel-meat (element) thermal expansion coefficient

- Exothermic energy release upon heating

- Fuel-element mechanical properties

- Fuel-meat and fuel-element irradiation properties

- Fission density distribution 
- Fuel-element swelling

- Fuel-meat swelling

- Fuel-meat and fuel-particle microstructures

- Fuel-element mechanical integrity

- $\quad$ Blister threshold temperature

- Cladding corrosion behavior

- Fission-product release

- Fuel-assembly properties

- Hydraulic and mechanical behavior

- Fuel-assembly irradiation behavior.

\subsection{Overview of Plan}

Execution of this plan using fuel test specimens that are produced in a manner that is prototypic and representative of the fabrication process that meets conversion requirements and is commercially viable and Base Fuel Qualification Plan generates the data required for detailed evaluation of the suitability of base fuel for USHPRR reactor conversions. Commercial viability implies acceptable cost and uraniumresource utilization. These data and analyses will be documented in the Base Fuel Qualification Report, which will be submitted to NRC. It is anticipated that generic approval for the use of this fuel will be granted through the issuance of NUREG document by NRC. Reactor-specific fuel-element performance will be demonstrated through the execution of DDE testing prior to reactor conversion. The primary deliverable that results from execution of this plan is a qualified base-fuel design.

The FD pillar provides extensive characterization and out-of-pile testing of fabricated fuels, and performs irradiation and post-irradiation examination (PIE) in a series of tests that generate data for qualification of the selected base fuel, and determines performance of the selected fuel under the range of conditions required to support reactor conversion. Data requests are incorporated into the individual test plans to ensure the requested and required data are provided.

The information generated by FD is communicated to FFC and RC. FD provides a fuel specification to FFC, which in turn provides FD with the fuel plates for insertion into the reactor, characterization data completed during fabrication, and a final fabrication summary report. Interactions between FFC and FD ensure fabrication parameters or concerns are incorporated into fuel design. FD works with RC to ensure the fuel design will meet the requirements for each specific reactor. $\mathrm{RC}$ provides FD with information on the reactor's operating envelope in the form of a fuel-test design input. Changes to the fuel design, fuelfabrication methods, and reactor requirements influence the fuel design and specification. Each pillar could introduce requirements that cause the other pillars to alter their planning and activities. This requires that the three pillars be integrated, developing requirements jointly and sharing test results as shown in Figure 2. A fourth pillar, Convert Integration has been added to integrate all cross-cutting activities necessary for the conversion scope.

The high-level conversion requirements that FD will accomplish to satisfy the USHPRR functions flow into the specific FD test plans for in-pile and out-of-pile tests. Testing envelope requirements for irradiation tests are documented separately in FOR-158 prepared by the DA with input from FFC, RC, and FD. ${ }^{11}$ FFC requirements related to fabrication resources and material availability must be incorporated into test plans. After publication of the Base Fuel Qualification Report and generic acceptance of the fuel by the regulator, FD will continue to provide data and analysis to support the DDE tests and licensing of the fuel system for each reactor. 


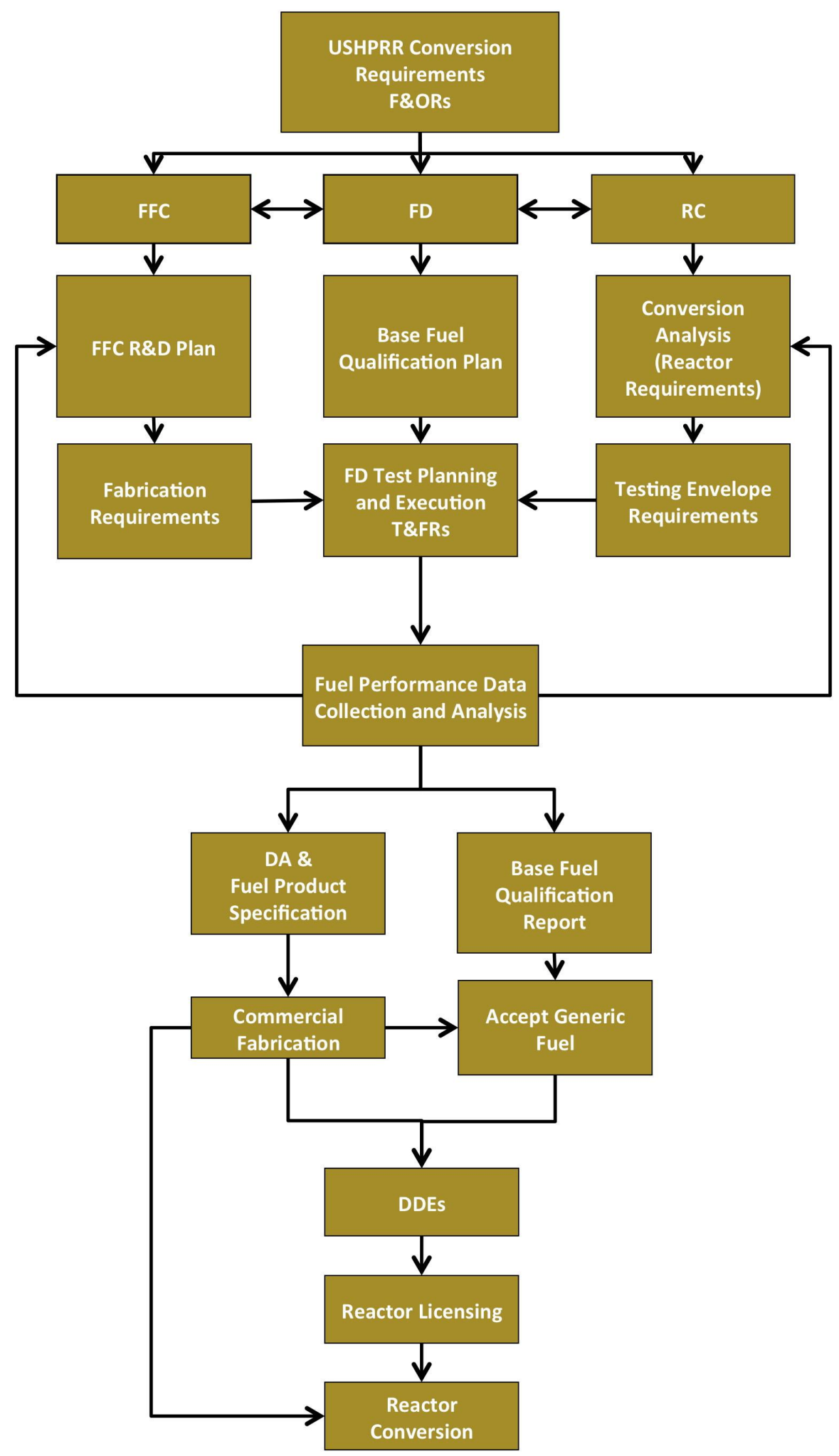

Figure 2. Flow of requirements and information for fuel qualification and licensing. 


\section{REQUIREMENTS FOR FUEL QUALIFICATION 2.1 Background on Requirements}

The NRC does not have a prescribed regulatory framework for the qualification of fuel for research reactors. Consequently, the USHPRR Conversion Program fuel-qualification process must rely on information from previous qualification campaigns (historical precedence) along with individual reactor requirements and IAEA guidance, to formulate both high-level and more specific lower-level requirements that, when satisfied, will lead to fuel qualification. These internally generated, programspecific requirements provide the framework for this Base Fuel Qualification Plan and the Base Fuel Qualification Report. The general steps in the fuel qualification process are shown schematically in Figure 3. The Base Fuel Qualification Report will contain the analysis of data integrated across all three pillars and document that the base-fuel design meets all applicable requirements. It is anticipated that there will be ongoing interaction with NRC after submission of the Base Fuel Qualification Report in order to respond to RAIs.

It should be noted that the process described here does not include a manufacturer-specific qualification as described in IAEA guidelines. Qualification of the manufacturer is through adherence to a manufacturing and quality plan and fuel specification accepted by the reactor. The plan and specification ensure that the fuel product is produced within the bounds of the originally qualified fuel. Fabrication process specifications used during fuel qualification and pilot-scale fabrication must be scalable to full production-process capabilities and capable of meeting quality-assurance requirements. After generic acceptance of the fuel by the regulator, the reactor operators will be provided a general LEU-fuel specification from the DA. They will then tailor it for their reactor-specific requirements, maintain technical ownership, and impose the requirement on the manufacturer for future LEU fuel procurement.

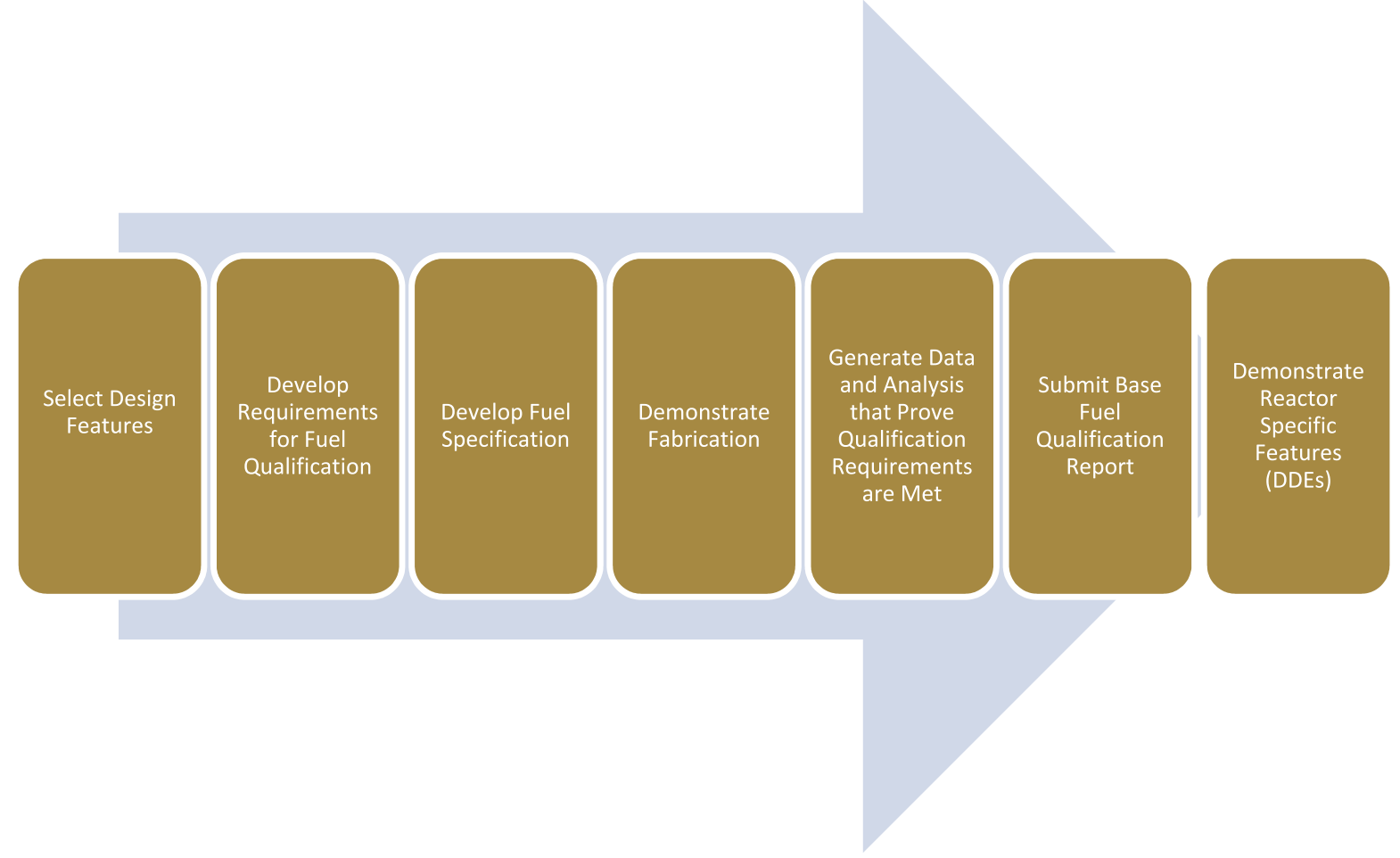

Figure 3. Schematic flowchart showing steps for USHPRR fuel qualification. 
Although not a formal requirement, successful execution of this plan relies on the use of fuel test specimens that are produced in a manner that is prototypic and representative of the fabrication processes that meet conversion requirements and are commercially viable. Commercial viability implies acceptable cost and uranium-resource utilization.

The full listing of the USHPRR functions and requirements applicable for fuel development, as stated in the USHPRR Program Functions and Requirements Document ${ }^{17}$ is included as Appendix A. Each of the functions and requirements are restated below, along with a further explanation of specific FD tasks to be conducted to ensure that each requirement satisfies each function.

This plan ensures that adherence to high-level requirements is demonstrated through testing and analysis. Implementation of tasks and lower-level requirements are established in lower-level planning documents such as irradiation-test control, characterization, and PIE plans. Activity-specific test plans provide the lowest level of requirements, including requirements for acceptance of test data.

In general, research-reactor fuel systems are not routinely tested to failure because of issues associated with release of fission products to the test reactor's primary coolant system. The testing approach taken is, therefore, to determine fuel operating requirements and test fuels under conditions providing sufficient margin to guarantee that in-service failures will not occur. Irradiation tests are designed to stop short of fuel failure and rely heavily on post-irradiation investigation of precursors to failure in the fuel system (i.e., the meat, diffusion barrier, and cladding). Additional testing to understand fuel-failure mechanisms is conducted out-of-pile.

\subsection{USHPRR Functions and Requirements}

The USHPRR Conversion Program has developed a set of Functions and Requirements based on historical precedence, information from previous research-reactor fuel-qualification efforts, and general guidelines for reactor conversion. ${ }^{17}$ Although these high-level requirements will generally guide planning and execution of the fuel qualification program, additional detail and specific lower-level requirements are defined here. Note that these requirements may be revised in the future as more information becomes available within the program.

Figure 4 shows a diagram of USHPRR high-level functional requirements. All of F 1.0 (Develop and Qualify Alternative LEU Fuel) is directly applicable to this fuel-qualification plan. Some aspects of F 2.2 (Fuel Fabrication) and F 2.3 (Regulatory Review) also apply to this plan. The RC and FFRC Pillars are responsible for other aspects of F 2.0 not addressed in this document. 


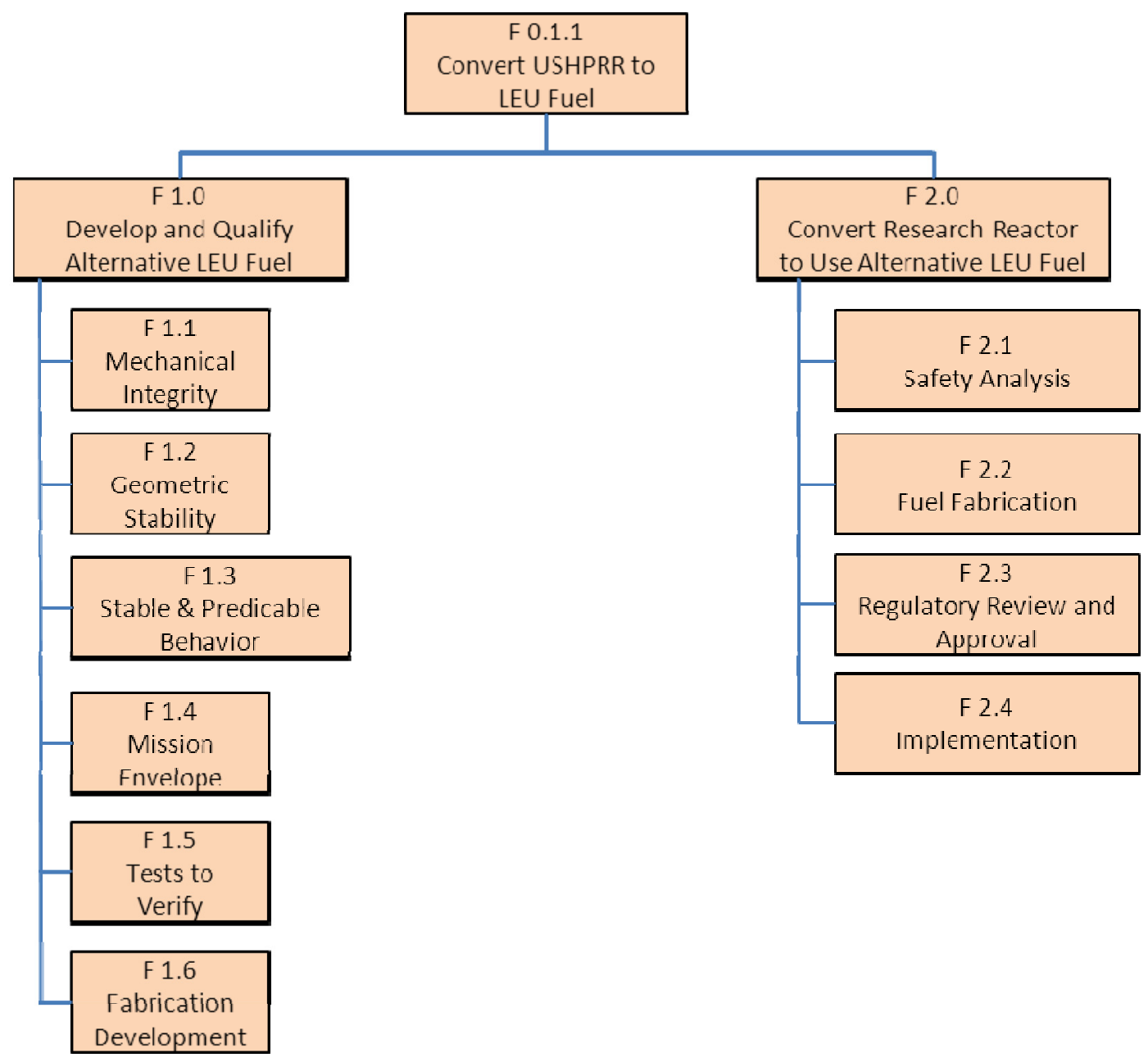

Figure 4. Structure of USHPRR functional requirements.

\subsubsection{Meeting Requirements for Base Fuel Qualification}

This section lists the applicable high-level USHPRR functions and requirements for generic acceptance of the base-fuel design, along with specific actions that FD has determined necessary to meet the requirements and demonstrate that all functions are satisfied. Based on the functions and requirements, and information from previous fuel qualification efforts, FD has established fuelperformance-testing protocols, with metrics, and established the data streams needed to evaluate these metrics. Some USHPRR requirements addressed here are primarily within the scope of FFC or RC, but are included because FD has a role in providing data or support.

\section{- F 0.1.1-Convert USHPRRs to LEU}

This high-level function provides overall objectives for the USHPRR Conversion Program and FD pillar.

- $\quad$ R 0.1: New LEU fuel shall be developed and qualified to convert USHPRRs from HEU fuel to LEU Fuel.

- $\quad$ R 0.5: The replacement LEU fuel shall meet the operating requirements of the existing license including both nuclear capability and safety margin.

- R 0.6: The alternative fuel shall have a U-235 concentration of less than $20 \%$. 
- F 1.0-Develop and qualify an alternative LEU fuel

This high level function provides overall objectives for the USHPRR Conversion Program and FD pillar.

- R 1.0.1: Development and qualification of a fuel system to convert USHPRRs from HEU fuel to LEU fuel shall use the framework of previous fuel qualification processes.

- R 1.0.2: A qualification report for the base LEU fuel shall be developed and submitted for regulatory review.

- R 1.0.3: Design features shall be selected to ensure that the fuel and cladding operate safely under all credible environmental and irradiation conditions during their life cycle at the reactor site.

- $\quad$ R 1.0.4: Generation of fuel qualification and safety analysis information shall be valid, applicable, and supported by referenced tests, measurements, and operating experience. This information shall include all applicable properties discussed in NUREG-1537, Part 1, Section 4.2.1.

- $\quad$ R 1.0.5: Ability to fabricate the new LEU fuels in laboratory and industrial environments shall be developed and demonstrated.

\section{- F 1.1-Maintain Mechanical Integrity}

This function ensures the fuel retains fission products to prevent their release to reactor cooling water. This function relates to the structural integrity required to prevent release of fission products that are generated during fuel burnup. Fission-gas retention may be achieved by incorporation of gases within the microstructure of the fuel meat or by containment within either the diffusion barrier or the cladding. Potential fuel-failure mechanisms include those related to physical or chemical processes in the reactor or manufacturing defects. Mechanical integrity is defined to mean that no breach occurs in the cladding that releases fission products under normal fuel operating conditions or under anticipated transients.

- R 1.1.1: Physical properties related to fuel integrity shall be established.

Establish through documentation that thermal and physical-property data are sufficient for analysis of fuel structural integrity and simulation of fuel system performance. This includes the fuel meat, diffusion barrier, cladding, and interfaces.

- R 1.1.2: Mechanical response of fuel meat, cladding, and any interlayers during normal operations and anticipated transients shall be established.

a. Establish that fission-product release does not occur during irradiation of fuel under base-fuel USHPRR operating conditions and normal handling

b. Establish that irradiation-induced changes to fuel properties and microstructure do not lead to loss of fuel-system mechanical integrity

c. Establish that the diffusion-barrier mechanical integrity is maintained and maintains function throughout its service life

d. Establish that cladding mechanical integrity is maintained during irradiation under base fuel USHPRR operating conditions and normal handling evolutions

e. Establish through analysis internal mechanical stress and strain under mechanical, thermal, and hydraulic loads for base-fuel USHPRR irradiation conditions.

- R 1.1.3: The fuel plate ${ }^{\mathrm{a}}$ shall not delaminate during normal and anticipated transients.

a. Establish that no delamination of fuel-cladding or cladding-cladding interfaces occurs during irradiation under base-fuel USHPRR normal operating conditions

a, Slightly modified wording from the US High Performance Research Reactor Project Functions and Requirements, August 2014. 
b. Establish that irradiation-induced changes to fuel properties or microstructure do not result in fuel delamination under base-fuel USHPRR normal operating conditions

c. Establish, through post-irradiation blister threshold testing and analyses, that delamination does not occur for operation under anticipated transient base-fuel USHPRR operating conditions.

- $\quad$ R 1.1.4: Limits for fabrication defects shall be established.

a. Establish the role of fabrication defects and defect limits in maintaining fuel structural integrity, geometric stability, and stable and predictable behavior.

b. Establish the role of fabrication defects in any observed fuel failures. Document these limits in the Fuel Product Specification through the DA.

- $\quad$ R 1.1.5: Water corrosion limits for the cladding shall be established.

a. Establish that the fuel thermo-mechanical processing route and materials selected do not result in excessive corrosion in test reactor irradiations under heat flux and temperatures representative of base-fuel USHPRR fuel operating conditions.

b. Oxidation pretreatment requirements will be established by the reactor operator for each reactor being converted.

\section{- F 1.2-Maintain Geometric Stability}

This function is to ensure the unrestricted passage of reactor coolant, as required by fuel element design, is maintained to prevent overheating and hot spots in the fuel. Overheating and hot spots may lead to accelerated corrosion or mechanical failure of fuel. This function relates primarily to maintaining fuel system coolability, which is critical to maintaining mechanical integrity in the fuel. Distortions in the fuel plates can interfere with the inter-plate flow channels, resulting in a decrease in cooling water contact with the fuel. Increased temperatures leads to increased corrosion of the plate surface and, consequently, increased fuel-meat temperatures. Understanding of the geometric stability of the fuel system is necessary for assessment of fuel suitability for use.

- $\quad$ R 1.2.1: Geometry of fuel shall be maintained during normal and anticipated transients.

a. Establish that no in-reactor blistering occurs during irradiation testing for the range of normal base fuel USHPRR reactor operating conditions

b. Establish that blister-threshold temperature measured out-of-pile is sufficient to prevent blistering of fuel plates for the range of base-fuel USHPRR anticipated transient conditions

c. Establish through analysis and documentation the role of fabrication defects in maintaining fuel-system geometric stability.

- $\quad$ R 1.2.2: Data shall be documented for material properties that affect geometric stability and thermal-hydraulic analysis. Effect of fuel burnup on properties shall be evaluated, as necessary.

a. Establish through analysis and documentation thermal- and physical-property data sufficient for analysis of fuel geometric stability and to perform thermal-hydraulic analysis.

- R 1.2.3: Fuel performance and structural stability shall be maintained so that reactor-coolant flow maintains fuel-plate heat transfer and/or temperatures within the reactor SAR envelope.

a. Establish, through irradiation testing under normal USHPRR operating conditions, that fuelperformance-related phenomena (e.g., swelling, creep) do not result in geometry changes that lead to a loss of coolability due to flow instability

b. Establish, through post-irradiation testing, that irradiation-induced degradation of properties (bond strength, fuel strength) does not lead to conditions (e.g., fuel meat fracture, blistering) that result in a loss of coolability due to flow instability under anticipated transient conditions. 
- R 1.2.4: Plate movement caused by pressure differential shall not compromise ability to cool fuel.

a. Establish, through flow testing of generic fuel plates and thermal-hydraulic simulation that operation of fuel plates under base-fuel USHPRR normal operating conditions and anticipated transients does not lead to plate distortion (e.g., bowing, twisting, buckling, warping), deformation, or movement that compromises the ability to cool the fuel

- R 1.2.5: Changes in channel gap shall not compromise ability to cool fuel.

a. Establish, through irradiation testing under normal USHPRR operating conditions, that fuel swelling does not result in channel-gap closure that compromises the ability to cool the fuel

b. Establish, through post-irradiation testing, that fuel blistering does not result in channel-gap closure that compromises the ability to cool the fuel under normal base-fuel USHPRR operating conditions and anticipated transients

c. Establish, through irradiation testing, that surface oxide growth does not restrict the channel gap and compromise the ability to cool the fuel in test-reactor conditions under normal basefuel USHPRR heat flux and surface-temperature conditions.

d. Establish through flow testing of generic fuel plates and thermal-hydraulic simulation that operation of fuel plates under base-fuel USHPRR normal operating conditions and anticipated transients does not lead to plate distortion (e.g., bowing, twisting, buckling, warping), deformation or movement that compromises the ability to cool the fuel

\section{- F 1.3: Stable and Predictable Behavior}

This function ensures that the fuel provides consistent, repeatable behavior within a range of fabrication tolerances specified in fuel-element-design documentation, over the required number of reactor cycles, and over a range of power and fission densities expected during normal operation and anticipated transients. This function relates primarily to the fundamental irradiation behavior of the fuel meat and the development of interaction layers. The purpose of this requirement is to establish that the fuel performs in a predictable manner that remains within the reactor safety basis.

- R 1.3.1: Fuel performance shall be known and predictable for the expected range of fuel composition and impurities, processing parameters, and microstructure for all credible environmental and irradiation conditions.

a. Establish through microstructural evaluation of fuel, that the fuel is operating in a stable and predictable regime, with no features indicating that undesirable changes in behavior are imminent

b. Establish, through post-irradiation examination, that blister-threshold temperature is known and predictable for fuel irradiated under normal base-fuel USHPRR operating conditions and anticipated transients.

- R 1.3.2: Physical properties and fuel features that are important for the analysis of fuel stability under irradiation shall be documented.

a. Establish, through measurement analysis and documentation, thermal and physical-property data sufficient for analysis of fuel stability under irradiation.

- $\quad$ R 1.3.3: Fuel swelling behavior shall be within the stable swelling regime (linear and predictable).

a. Establish, through irradiation testing and PIE, that the selected fuel design and fabrication process exhibit a repeatable functional relationship between swelling and irradiation conditions

b. Establish that the fuel does not exhibit break away swelling or pillowing under normal basefuel USHPRR operating conditions, fission densities, and fuel temperatures 
c. Establish through microstructural evaluation of fuel, that fuel is operating in a stable and predictable swelling regime and that breakaway swelling is not imminent.

- R 1.3.4: Compatibility of uranium-molybdenum (U-Mo) fuel with reactor coolant shall be established to cover the case where a cladding breach may occur under normal operating conditions.

a. Establish the chemical interaction behavior between water and U-Mo and fission-product release after cladding breach using irradiated fuel plates or fuel plate components.

- R 1.3.5: Irradiation behavior on (geometric and fabrication) scale-up shall be predictable.

a. Establish, through irradiation of mini-plates, prototypic base-fuel USHPRR full-size fuel plates, and fuel test assemblies, that the swelling behavior of fuel plates remains stable and predictable for all base-fuel USHPRR fuel plate sizes and geometries under the range of normal base-fuel USHPRR operating conditions

b. Establish, through post-irradiation blister testing of prototypic base-fuel USHPRR full-size fuel plates and fuel test assemblies, that fuel blister-threshold temperature remains stable and predictable for all base-fuel USHPRR fuel-plate sizes and geometries under the range of normal USHPRR operating conditions

c. Establish, through testing of prototypic base-fuel USHPRR full-size fuel plates and fuel test assemblies and through analysis, that the mechanical integrity (i.e., resistance to fissionproduct release) of all base-fuel USHPRR fuel plate sizes and geometries is stable and predictable under the range of normal base-fuel USHPRR operating conditions

d. Establish, through testing of prototypic USHPRR full-size fuel plates and fuel test assemblies and through analysis, that all base-fuel USHPRR fuel plate sizes and geometries are geometrically stable (i.e., ability to be cooled is maintained) under irradiation over the range of normal base-fuel USHPRR operating conditions.

\section{- F 1.4: Establish Reactor Mission Performance Envelope}

This function ensures that the fuel system operating envelope is established so that testing within the established envelope verifies performance equivalent to current HEU fuels. This function relates primarily to the operating envelope safety, cost, and performance characteristics of the reactor using the LEU fuel.

- R.1.4.1: Use-related performance characteristics of the reactor shall not be degraded significantly by the fuel conversion.

a. Establish that fuel-plate and fuel-element designs provide equivalent or near-equivalent performance to HEU fuel elements so there is not a significant reduction in the operating envelope of base-fuel USHPRRs upon conversion.

- R 1.4.2: Changes in nuclear capabilities resulting from conversion to LEU fuel shall not result in a significant decrease in the safety margin of the reactor.

a. Establish, through irradiation testing and analyses, that fuel plates and fuel elements are designed so that fuel performance does not result in a significant reduction in base-fuel USHPRR safety margin.

- R 1.4.3: Performance envelope for normal operations and anticipated transients shall be established.

a. Verify, through irradiation testing and analyses of the selected fuel design and fabrication process, that the base-fuel exhibits suitable performance within the USHPRR base-fuel operating envelope, including peak volumetric heat-generation rate, peak surface-heat flux, and peak fission density during normal operation and anticipated transients. 
b. Verify, through post-irradiation measurement of the blister-threshold temperature and analyses, that the fuel exhibits suitable blister resistance when irradiated within the bounding envelope for peak heat-generation rate, peak surface heat flux, and peak fission density during normal operation and anticipated transients.

- $\quad$ R 1.4.5: The selected fuel element designs shall be qualified within the set of bounding geometric configurations and irradiation conditions for each USHPRR. ${ }^{\mathrm{b}}$

\section{- F 1.5 Test to Verify Design Requirements Have Been Met}

This function relates to engineering design verification of fuel behavior at the scale of integral fuel elements. Fuel plates, when combined as fuel elements, must function in the same manner as demonstrated during fuel-plate testing.

- R 1.5.1: Verification (tests, reviews, analysis) shall be conducted and documented to demonstrate that fuel elements are designed to accommodate expected mechanical forces and stress, hydraulic forces, thermal changes and temperature gradients, internal pressures (including those from fission products and gas evolution), and radiation effects, including the maximum fission densities, fission rates, and fuel temperatures.

a. Establish, through analyses, the anticipated mechanical forces and stresses, hydraulic forces, thermal stresses, and internal pressures to which fuel plates and fuel elements will be subjected.

b. Establish, through analyses of the mechanical response of full-size base-fuel USHPRR conversion fuel plates under simulated base-fuel USHPRR irradiation conditions, that the irradiation response of full-size fuel-plate geometries is stable and predictable.

- R 1.5.2: Full-size fuel elements, which may be of a generic configuration but are prototypic of at least one of the higher-performance reactors shall be irradiated under conditions that exceed those of their intended use by a comfortable margin. ${ }^{\mathrm{c}, \mathrm{d}, \mathrm{e}}$

a. Verify fuel performance on the fuel-element scale, through prototypic fuel-element irradiation testing of two fuel elements fabricated using the selected fuel fabrication process and fuel design and irradiated under the operating conditions (peak fission rate, peak temperature, and maximum fission density) that bound operating parameters for NRC regulated USHPRRs.

b. Establish, through post-irradiation examination of fuel test plates from fuel element tests, that requirements for mechanical integrity, geometric stability, and stable and predictable behavior are met for NRC-regulated USHPRR.

c. Verify through post-irradiation measurement of the blister-threshold temperature of fuel plates from fuel element tests, that the blister threshold temperature is sufficient to meet requirements for NRC-regulated USHPRRs.

b. Slightly modified wording from the US High Performance Research Reactor Project Functions and Requirements, August 2014

c. Comfortable margin is defined to mean a peak fission rate and temperature equal to peak values expected during normal operations, a time history representative of expected normal reactor operations, and a fuel burnup well in excess of expected discharge during normal use.

d. If reactor fuel element designs require fission densities equivalent to full LEU burnup, it is not possible to achieve burnup 'well in excess' of the LEU burnup when testing with LEU.

e. This requirement applies to testing of prototypic fuel elements with the purpose of meeting requirements for conversion of NRC-regulated USHPRRs. This testing is designed to be performed under representative operating conditions, but may not be bounding. This testing also contributes directly to qualification of fuel for ATR, but is not conducted under bounding ATR conditions. 


\subsubsection{Requirements for Post-Qualification Fuel Acceptance}

It is anticipated that, upon meeting all of the previously listed requirements, a Base Fuel Qualification Report specific to NRC-regulated reactors will be submitted to the NRC. Upon resolution of RAIs, acceptance that the generic base fuel design is suitable for use will be documented in a NUREG. After generic acceptance, the FD pillar will continue to provide data and analysis to the USHPRRs, RC and FFC, and the DA to facilitate licensing of the base fuel for each specific base-fuel USHPRR.

\section{- F 1.6 Fabrication/Manufacturing Development and Qualification}

This function relates to the qualification of the process used to fabricate and manufacture the selected fuel system design. Process and product specifications must guarantee that the fuel product will meet performance requirements.

- R 1.6.3: Fabrication process specifications and acceptance criteria for prototype fuel-elements shall be based on the results of fuel characterization and manufacturing evaluations.

a. Establish a generic Fuel Product Specification and acceptance criteria to ensure product consistency during fuel qualification. Irradiation test plates for fuel qualification shall be made in accordance with this specification.

b. Establish reactor-specific conversion fuel-element specifications and acceptance criteria prior to irradiation of lead test elements or DDE fuel elements.

c. Establish DDE fuel specifications based upon the reactor conversion element specification and acceptance criteria.

\section{- $\quad$ F 2.2 Fabrication}

This function relates to fabrication of the selected fuel-system design. Only the requirements pertaining to DDEs and the Fuel Product Specification controlled by the DA are listed here.

- $\quad$ R 2.2.2: Fuel elements for a specific reactor shall be fabricated and tested to support the development of the reactor-specific conversion safety analysis.

a. Establish that lead test elements or prototypic DDE fuel elements are fabricated according to specifications and acceptance criteria applicable to production fuel elements.

- $\quad$ R 2.2.4: Acceptance criteria used for manufacturing fuel elements shall be based on the base fuel qualification, reactor-specific conversion safety analysis, and manufacturing evaluations.

a. Establish that a generic Fuel Product Specification and acceptance criteria are developed and maintained by the DA during generic base fuel qualification.

b. Establish that reactor-specific USHPRR conversion fuel-element specifications and acceptance criteria are developed prior to lead-test-element or DDE testing.

c. Establish that reactor-specific USHPRR conversion fuel-element specifications and acceptance criteria are reviewed and analyzed prior to lead test element or DDE testing to ensure that the specification and acceptance criteria results in a product that meets fuel performance specifications.

\section{- $\quad$ F 2.3 Regulatory Review and Approval}

This function relates to NRC approval of the selected fuel-system design. Only the requirement pertaining to DDE tests is listed here. This section does not apply to reactors not regulated by the NRC.

- $\quad$ R 2.3.2: The reactor licensee, with USHPRR Project support, shall provide additional safetyanalysis data from demonstration tests to the NRC at a time to allow sufficient review prior to the end of the NRC's review period. 
a. Establish that lead test elements or DDEs are irradiation tested to demonstrate design specific features of reactor fuel elements.

b. Establish that lead test element or DDE test designs shall be reviewed prior to irradiation to ensure that reactor-specific design features are incorporated into the test design.

c. Establish that lead test element or DDE test designs are reviewed prior to irradiation to ensure that the test conditions bound those of the converting reactor.

d. Establish suitability of the fuel design by demonstrating: 1) Adherence to the fuel specification and acceptance criteria 2) Demonstration that fuel qualification requirements are met through, pre-irradiation characterization, out-of-pile testing, demonstration of in-reactor performance, and post-irradiation examination and testing. 


\section{APPROACH TO FUEL DEVELOPMENT AND QUALIFICATION}

To gather the data needed to demonstrate that the requirements listed in Section 2 are met, welldefined test articles are fabricated, characterized, irradiated in ATR, and examined to quantify irradiation effects. Unirradiated components and fuels are examined to quantify the effects of fabrication variables on fuel performance, and to gather basic data on component and fuel properties in the absence of a radiation field. This section describes the tests and analyses to be conducted on test articles, and describes the irradiation tests to be conducted.

\subsection{Continuous Design Improvements}

As described in Section 1.2, the base-fuel design selected for development is a very-high-density plate-type fuel comprising a U-Mo-alloy fuel foil having $\mathrm{Zr}$ diffusion barrier interlayers, encapsulated in 6061 aluminum alloy cladding. ${ }^{3}$

The GTRI program has performed a series of fuel tests since 2005, using laboratory-scale fabrication processes that have established the viability of monolithic research reactor fuels based on U-Mo alloys. The base-fuel design represents a significant departure from existing dispersion fuel technology because the entire fuel zone is replaced by a monolithic U-Mo alloy foil ${ }^{18}$ and because several of the manufacturing process steps are substantially different.

A commercial-scale fabrication line and associated fabrication processes will be developed by the USHPRR program, with the goal of selecting an optimized process that provides a product that meets fuel-performance requirements at an acceptable cost. A description of the research and development being conducted is found in the Fuel Fabrication Capability Research and Development Plan. ${ }^{18}$ The results of this research and development will be used to establish an improved baseline fabrication process that is designed to accommodate full-scale production requirements.

New fabrication variables and alternative fabrication processes introduced by fabrication-process development require an irradiation testing program that provides quantitative data allowing selection of the fabrication process. These concepts will be included in the MP-1 irradiation test (described in Section 4.2.1) to determine whether fuel performance associated with optimized or new fabrication processes is adequate to meet USHPRR reactor requirements. A final selection of the fuel design and fabrication process technology will be made as a result of the MP-1 test.

Beyond MP-1, maintenance and configuration control of the base fuel design specification is the ongoing responsibility of the DA. Design improvements may include incorporation of features that are intended to address fuel performance or changes in operating conditions, as well as development and approval of fuel product and fabrication process specifications, test and inspection methods, acceptance criteria, qualification plans for manufacturing processes, and quality assurance procedures.

\subsection{Fuel Irradiation Testing}

\subsubsection{Mini-plate Testing}

Mini-plate tests are small-scale tests used for scoping, selection of the fuel design, and increasing statistical confidence. Mini-plates allow more individual plates to be tested in the limited reactor space available, allowing more conditions to be tested and more variables to be observed with better statistics. Mini-plate testing is performed to allow investigation of a wider variety of fabrication and fuelperformance variables, a wider range of irradiation conditions, and improved performance statistics. The small size of the test plates allows more than 30 test specimens (which can have nearly identical or different irradiation conditions) to be investigated per test vehicle, rather than the 2-6 that are possible when performing a full-size plate irradiation.

Mini-plates included in fuel-qualification testing will be fabricated from full-size foil specimens and assembled into test plates using a fabrication process that is representative of commercial production. 


\subsubsection{Full-size Plate Testing}

Full-size plate testing provides proof of performance for prototypic-scale geometries as well as providing more representative testing conditions due to reduced power gradients in the specimens. Reactor conditions used in full-size plate tests are more prototypic and more representative of power profiles under USHPRR operating conditions.

Each full-size fuel plate requires an order-of-magnitude larger test volume than a mini-plate. Reactor space and configuration thus allow a reduced number of test plates in each irradiation campaign relative to mini-plate testing, resulting in lower-statistical-confidence data from each test. Fewer test conditions and fewer test-plate geometries can be explored.

Full-size-plate testing, combined with mini-plate testing, provides confidence that fuel-element demonstration tests can be conducted with low risk of failure. Fuel failure during fuel-element testing can lead to program setback in addition to loss of data.

Full-size plates are fabricated using representative equipment and processes on a fuel production pilot line.

\subsubsection{Fuel-element Demonstration}

Fuel-element demonstration testing requires that a repeatable pilot-scale fabrication process is in place and qualified. Element testing provides a prototypic environment for testing generic fuel elements that represents, as closely as possible, axial, radial, and azimuthal power shape and flow conditions of the test reactor in which the elements are being tested.

Test conditions for each plate are defined by the element test environment, so it is not possible to have independent test conditions for each plate within the element. Substantial data are collected using full-size plates and mini-plates prior to fuel-element demonstrations to ensure a low risk of failure.

The first fuel-element demonstration tests serve as the final demonstration of fuel-system behavior prior to submittal of the Base Fuel Qualification Report. Testing of multiple fuel elements continues to provide increased confidence in fuel-performance and fabrication repeatability prior to reactor conversion.

\subsubsection{Design Demonstration Elements}

A final series of irradiations of reactor-specific fuel element geometries in reactor-specific fuel element configurations is used to provide a performance demonstration of the final fuel-system design and fabrication process. DDEs demonstrate performance of reactor-specific fuel designs through irradiation of either full reactor elements (in the case of MURR and ATR) or prototypic element assemblies that represent key fuel-element-design features (as with NBSR and MITR) for each of the base fuel reactors. DDEs are irradiated under conditions designed to be as prototypic of actual reactor operating conditions as possible outside of the environment of the converting reactor. Based on function F 1.5, fuel-element demonstration tests will be conducted on test-fuel elements under conditions that exceed those of their intended use by a comfortable margin.

Concurrent with the DDEs, hydraulic testing of actual conversion elements in a flow test loop will be conducted to further ensure mechanical integrity and geometric stability. After completion of element testing, DDE testing, flow testing of conversion elements, and completion of analyses required for reactor conversion, the USHPRR Conversion Program anticipates NRC approval for LEU conversion of USHPRR base-fuel reactors. 


\subsection{Post-irradiation Examination}

PIE is conducted to verify that fuel tested in-reactor meets fuel performance requirements for the required range of USHPRR operating conditions. Post-irradiation examinations verify adequate mechanical behavior, geometric stability, stable and predictable behavior, and performance on scale-up. Fuel plates are examined and results are analyzed and interpreted to understand fuel behavior, material response, and investigate precursors to failure. PIE includes the following activities, discussed in detail below:

- Channel-gap measurement

- Ultrasonic scanning of individual full-size test plates

- Visual examination

- $\quad$ Test fixture and fuel plates while retained in the test fixture

- Test plates after removal from the test fixture

- Radiographic inspection of fuel elements and fuel plates

- Oxide-thickness measurement

- Plate-thickness measurement

- Measurement of fuel-plate density

- Gamma scanning

- Optical metallography

- Electron microscopy.

Non-destructive PIE is typically performed on all fuel plates, while destructive techniques are typically performed on approximately $50 \%$ of the irradiated plates.

\subsubsection{Channel-gap Measurement}

The coolant-channel-gap width is measured in the reactor canal prior to irradiation, between irradiation cycles, and after the final irradiation cycle. Channel-gap width measurements are conducted on element or mini-element fuel test configurations that constrain test plates within a side plate. Channel-gap width measurements are used to confirm mechanical integrity and dimensional stability of fuel plates by providing indication of delamination, blistering, or element-geometry changes that manifest as a change in coolant channel gap dimensions.

\subsubsection{Ultrasonic Scanning}

Ultrasonic scanning of irradiated fuel is used as a method to measure fuel-plate thickness and confirm the absence of debonded or delaminated areas in the fuel plates. The ultrasonic measurement system is located in the reactor canal and can be used for full-size flat fuel plates. Ultrasonic scanning is typically conducted prior to irradiation, between irradiation cycles, and after the final irradiation cycle.

\subsubsection{Visual Examination}

Visual examination of irradiation test assemblies is conducted and recorded prior to irradiation, between irradiation cycles, after the final irradiation cycle, and upon receipt at the hot cell. Visual examination of the test assembly is used as an indicator that the test assembly performed as designed and that fuel test plates performed as designed.

Detailed visual examination is conducted after test disassembly to:

- Verify indications noted on previous examinations 
- Identify fuel-plate damage caused by handling or disassembly

- Identify areas of discoloration that may indicate cladding breach, anomalous oxide growth, spallation, or other issues

- Identify blisters or pillows

- Identify fuel-plate distortion (bowing, cupping, twisting, etc.)

- Identify and catalog any other features that are unusual or anomalous.

\subsubsection{Radiographic Inspection}

While radiographic examinations of irradiated test plates are typically performed following capsule or element disassembly, examinations may be performed prior to disassembly to verify that fuel plates contained within a test assembly or element do not show indications of loss of mechanical integrity or geometric stability. Neutron tomography can be used to measure fuel-element channel-gap width prior to disassembly. When performed following disassembly, individual plates are transferred into the appropriate fixture, facilitating a more detailed radiographic exam. Tomographic examination of fuel plates using radiography may also be performed before and after capsule or element disassembly to delineate indications on individual fuel plates and facilitate measurements of the channel-gap width. All examinations are performed per the experiment-specific PIE characterization plan.

\subsubsection{Oxide Thickness Measurement}

Oxide thickness is measured using eddy-current methods and confirmed using optical metallography. Oxide-thickness data are used to ensure fuel-surface temperatures were in the range expected during irradiation, fuel temperatures can be accurately calculated, and oxide thickness is appropriately corrected for in-plate thickness and density measurements.

\subsubsection{Plate Thickness Measurement}

Local plate-thickness measurements (profilometry) are taken to map local variations in plate thickness caused by differences in fission density, fuel creep, blistering, or delamination. Fuel-platethickness data are corrected for oxide growth and cladding thickness to provide local fuel meat thickness and fuel-swelling data.

\subsubsection{Plate Immersion-density Measurement}

Plate immersion density measurements provide average plate-swelling values for the range of operating conditions over the plate volume. Plate immersion-density measurements are corrected for cladding and oxide thickness to provide average fuel-meat swelling.

\subsubsection{Gamma Scanning}

Gamma scanning maps the location of fission products within the plate volume. Gamma scanning provides indications of fission-product loss, fission-product transport, and fuel relocation. Gamma-scan data are correlated with local plate-thickness and radiography data.

\subsubsection{Optical Metallography}

Optical metallography is a destructive microscopic examination used to observe the fuel meat, cladding, and interfaces for indications of unstable behavior. These indications, which may not be evident on external examination, include the presence of large gas bubbles or voids, fuel-meat cracking, cladding tearing, delamination of the cladding, and delamination of the fuel-to-cladding interface. Metallography data are correlated with data from visual examinations, radiography, thickness measurement, oxide thickness, and gamma scanning. 


\subsubsection{Electron Microscopy}

Electron microscopy provides the information necessary for a detailed understanding of fuel behavior and fuel-failure mechanisms. Detailed understanding of fuel behavior and fuel failure mechanisms, coupled with fuel modeling, provide confidence that fuel failures will not occur within bounding USHPRR operating conditions. Electron microscopy provides data on features that are not typically visible on examination using optical metallography or other examination methods, including breakdown of the fission-gas-bubble super-lattice, fission-gas-bubble connectivity that may be a precursor to breakaway swelling, the evolution of impurity phases (such as carbides and oxides) that may be important to performance, the performance of molybdenum-depleted regions in the fuel, and the evolution of phases and degradation of the fuel-to-cladding interface.

\subsection{Out-of-Pile Testing and Analysis}

Additional out-of-pile testing of unirradiated and irradiated fuel is conducted to collect data necessary to support qualification requirements and support fuel-performance modeling. These tests may be conducted on fuel plates prior to insertion in the reactor, on archive plates that are manufactured in parallel with plates that are irradiated, and on plates after irradiation. Included in these tests are microstructural characterization, material-properties characterization, fission-product-retention testing, integrated fuel-behavior modeling, and hydraulic testing. A major goal of out-of-pile testing is to understand the linkages between fabrication, microstructure, properties, and fuel performance. These tests include:

- Mechanical property measurement

- Off-normal testing

- Measurement of thermo-physical properties

- Bond strength measurement

- Hydraulic flow testing

- Fission gas release measurement

- Microstructural characterization

- Fuel performance modeling

- Residual stress measurement.

Additional scope details are provided in the USHPRR Conversion Program Scope Document. ${ }^{19}$

\subsubsection{Mechanical Property Measurement}

Mechanical properties testing on U-Mo monolithic fuel and cladding materials provides required data that support assessment of mechanical integrity, geometric stability, and stable and predictable behavior.

Mechanical testing of unirradiated fuel is used to provide data on the linkages between material chemistry, process parameters, microstructure, and mechanical properties. Mechanical property measurements on irradiated fuel provide information on the evolution of properties under irradiation and, along with the results of pre-irradiation materials-properties testing, allow the impact of fabrication and irradiation variables on materials properties to be related to overall fuel performance. Mechanical testing of irradiated fuel also provides critical data needed for understanding and analysis of failure mechanisms in fuel plates, including fuel-failure threshold. The results of mechanical-testing activities feed into the Fuel Product Specification, fuel-performance analysis, and the Base Fuel Qualification Report. 


\subsubsection{Off-normal Testing}

Margin to fuel failure has historically been determined for off-normal conditions by post-irradiation blister testing of research-reactor fuel. The blister-threshold temperature is established by post-irradiation heating of fuel plates to determine the temperature at which release of fission gas results in a raised area on the surface of the fuel plate. It is assumed that at this temperature, the fuel plate no longer meets requirements for operation within the reactor safety basis. ${ }^{20,21,22}$ The blister-threshold temperature is significantly affected by accumulation of fission products. A common blister test method is to heat, hold at temperature, remove, visually examine, and return a fuel sample to the furnace at successively higher temperatures until visual evidence of a blister is seen. ${ }^{23,24}$ The test is then concluded.

Because the internal mechanical response of monolithic fuel differs during in-reactor power excursions and out-of-reactor testing, the evolution of stress in the system during both in-reactor events and out-of-pile testing will be analyzed. Blister-threshold temperature data will be collected on all fuel irradiation and demonstration tests to establish the blister-threshold temperature over the range of NRC USHPRR operating conditions, fission densities, and plate geometries. Approximately $50 \%$ of fuel plates irradiated during fuel development and qualification are blister tested.

\subsubsection{Measurement of Thermo-physical Properties}

Thermo-physical property measurements are used to ensure that the internal plate-operating temperatures are quantifiable, and that temperature-dependent behavior-such as fission-gas-driven swelling, blistering, thermal stresses, and interdiffusion rates - can be predicted. The fidelity and type of measurements required are defined by the data needs for irradiation-test safety analyses and the needs of the RC pillar and the USHPRRs to support safety analysis.

This activity includes development of techniques and equipment to evaluate thermo-physical properties of fresh and irradiated fuels and conducting measurements on historical samples.

Measurements include laser-flash thermal diffusivity and specific heat capacity as a function of temperature and burnup, and room-temperature density measurements as a function of burnup. Metallography, microscopy, and chemical analysis are conducted as needed for correlation development. The product of the work is a validated temperature- and burnup-dependent thermal-conductivity correlation which will support submission of the Base Fuel Qualification Report and reactor safety analyses.

\subsubsection{Measurement of Bond Strength}

Bond-strength measurements focus on answering important questions related to fuel performance and the Fuel Product Specification. For example, fuel-cladding bond-strength measurements provide information about the resistance of fuel to delamination during reactor service, as well as an understanding of the mechanism for delamination, which are required to ensure that the cladding and fuel meat maintain intimate contact throughout irradiation. It is also necessary to understand whether the strength of the fuel-cladding bond prior to irradiation (which may be dependent on key fabrication process variables such as cold-rolling, or key microstructural features such as interaction-layer thickness) is correlated with post-irradiation bond strength and resistance to delamination.

Bond strength studies primarily involve laser-shock testing. Some additional activities involving alternative bond-strength-measurement techniques (such as bulge testing and micro-cantilever beam testing) are carried out to serve as a backup to the laser-shock technique and provide a method for benchmarking the laser-shock measurements. Knowledge of fresh-fuel bond strength from archive samples produced using the laboratory-scale fabrication process will allow the potential impact of changes during manufacturing-process development to be evaluated. Laser-shock studies on irradiated fuel will be conducted as part of PIE to determine the effects of fabrication variables and irradiation conditions on post-irradiation interfacial bond strength. 
Bond-strength assessments will also be performed to examine cladding-to-cladding bonding. It is recognized that sufficient cladding-to-cladding bond strength in monolithic fuel is required to ensure fission-product retention and that the hot-isostatic-pressing (HIP) fabrication process is fundamentally different from the current roll-bonding fabrication process used for dispersion fuels. While a particular value for the cladding-to-cladding bond strength may or may not be specified in the final Fuel Product Specification, a relative assessment of cladding-to-cladding strength in fuel plates produced by the HIP process, compared to the roll-bonding process, is needed. Cladding-to-cladding bonding assessments will be used in process development to define appropriate cladding preparation and cleaning procedures and will also be used to define the range of HIP-processing parameters to ensure acceptable cladding-tocladding bonding. Cladding-to-cladding bonding assessments may also be used in quality assurance to qualify the manufacturing process and to ensure that the process is operating under controlled, reproducible conditions known to yield acceptable bond strength.

\subsubsection{Hydraulic Flow Testing}

Flow testing provides information about the hydro-mechanical behavior of U-Mo monolithic fuel. It is also used to qualify the hydro-mechanical performance of USHPRR irradiation tests prior to their being installed in the test reactor. Flow testing reactor test designs prior to insertion is an opportunity to identify potential issues and avoid in-reactor failures.

Initially, a generic representation of U-Mo monolithic fuel, the Generic Test Plate Assembly (GTPA) will be compared to dispersion fuel in a series of representative tests. The GTPA is a modular mechanical assembly that can be used to house different types of test plates to compare the structural characteristics and dynamic response of materials including (1) a roll-bonded Al 6061-O plate, (2) an aluminum-clad DU-Mo monolithic foil plate representative of base fuel, and (3) an aluminum-clad, stainless steel surrogate dispersion fuel plate. The plates will be tested at selected flow rates under sub-cooled fluid-state conditions that represent reactor coolant temperatures and pressures. Each of these sets of plates will be tested under controlled thermal-hydraulic boundary conditions. The objectives of the tests are to:

- Identify the flow conditions that induce the onset of elastic plate deformation for each fuel plate material

- Identify the flow conditions that produce plate failure of each fuel plate material

- Identify the approximate flow conditions necessary to produce ultimate plate failure in either a static (large plastic deformation) or dynamic (plate vibration) state

- Provide test data for calibration of computational models.

Flow testing of USHPRR tests prior to final design is used to measure flow rates, identify potential fluid structure interaction (FSI) issues, and optimize fuel test design. Flow testing provides improved test design and analysis of test operating conditions, and reduces the risk of in-reactor test failure. Analysis of FSI is based on well-established codes interacting with one-another; however, this coupled interaction needs to be validated for complex geometries such as the USHPRR test trains.

\subsubsection{Fission Gas Release Measurement}

The U-Mo monolithic fuel system is anticipated to behave differently from current dispersion fuel plates with respect to fission-product migration and release mechanisms. Requirements for fissionproduct-release data for base-fuel USHPRRs are not clearly defined. The MITR reactor may require verification of iodine release from the fuel to ensure that off-site dose is within acceptable limits. Requirements for fission-product-release measurements for ATR and HFIR have not been defined, as discussed in Section 5 and Section 6 of this document.

Requirements for meeting off-site does limits related to fission-product release may be satisfied through any one of the following: 
1. Analysis of release and transport behavior by $\mathrm{RC}$ and the reactors

2. A simple method developed to provide information on iodine release, both after melting of the cladding and after melting of the fuel plat

3. Development of a more-complex system to provide time and temperature resolved data.

\subsubsection{Microstructural Characterization}

Microstructural characterization is a cross-cutting task that encompasses the detailed characterization of unirradiated fuel, irradiated fuel, and irradiated fuel after blister testing. Characterization is performed over the life of the USHPRR Conversion Program to improve understanding of how fabrication processing and irradiation conditions affect the microstructure of USHPRR base fuel and how the microstructure, in-turn, affects fuel irradiation performance during normal and anticipated transient conditions. The collected information is used to answer critical questions about the linkages between fabrication, microstructure, and fuel performance. Examples of these questions are: How does U-Mo alloy homogeneity affect fuel performance? How do impurities, such as carbon or oxygen that may appear as carbide and oxycarbide phases at the fuel-cladding interface, affect resistance to delamination? What features at the $\mathrm{U}-\mathrm{Mo} / \mathrm{Zr}$ interface are beneficial or detrimental to resistance to delamination? Answers to these questions allow the USHPRR Conversion Program to better define the microstructural requirements for the fuel system, which in turn defines fabrication processes and fabrication-process parameters.

Characterization objectives include providing data to support development of irradiation tests, providing information critical to the development and validation of a Fuel Product Specification, providing critical input into the fuel selection, and verifying fuel performance for the selected fuel technology. These activities result in a well-defined fuel product that is demonstrated to meet requirements for fuel stability under irradiation and requirements for off-normal performance.

\subsubsection{Fuel Performance Modeling}

Fuel-performance modeling is used to calculate fuel temperature, stress, and deformation for a given fuel design and operating conditions, and to analyze and define fuel failure criteria. When failure models are considered to be reliable, fuel failure conditions may be projected by comparing calculated values with failure criteria.

Since in-reactor behavior of fuel is complex, it is often difficult to separate variables during tests. A monolithic fuel performance model ${ }^{\mathrm{f}}$ will be used to test fuel design assumptions and fuel-performance hypotheses at a significantly reduced cost compared to irradiation tests. Performing simulated parametric sensitivity studies allows estimation of the importance of design variables on fuel performance. Parametric studies can also be used to determine which gaps in material- and system-property data are important and should be addressed. The fuel-performance model also serves an integrating function, where individual fuel-performance phenomena are combined and evaluated in the context of the complex irradiation environment.

The response to specific operating or upset conditions can also be evaluated, for example, to determine whether blistering or oxide spallation is likely to occur in a fuel over heating event. This is especially useful to analyze fuel performance for reactor tests. Fuel-behavior predictions are analyzed and reported prior to reactor insertion (based on the best available models) to uncover potential fuel performance issues during testing. After testing, fuel-performance data are fed back into the models to improve future predictions.

f. A commercial finite element code (ABAQUS) is currently used with embedded fuel behavior subroutines. The USHPRR program is currently evaluating the use of a MOOSE/Bison based fuel performance code. 
Fuel-performance modeling will be used to bridge a known gap in fuel qualification. Because of the inability to perform lead-test-element irradiations in the NRC USHPRRs, irradiation conditions of DDEs will not match those of conversion elements exactly. The benchmarked fuel-performance model will provide additional assurance that conversion fuel elements will perform adequately in lieu of lead-testelement irradiations.

\subsubsection{Residual Stress Measurement}

Residual stresses in as-fabricated fuel can be significant and are dependent on fuel processing conditions. It is not known how these stresses impact irradiation performance. Prior experience shows that residual stresses can play a significant role in manufacturing process development (e.g., by significantly affecting yields of both fuel foils and fuel plates) and, therefore, may need to be controlled. As a result, it is necessary to document what the residual stress state is for fuel foils and fuel plates manufactured by the current fabrication process.

Residual stress measurements on irradiated fuel will be used to determine the impact of fuel creep on irradiation behavior and the evolution of stresses that may be involved in failure of monolithic fuel plates irradiated to high burnup. Creep deformation of the fuel meat is necessary to relax the stresses generated by fuel swelling in the monolithic fuel system. The creep rate must be adequate to relax these stresses, at the lower bound of USHPRR fission rates. The creep rate also determines the stress state in the fuel after irradiation and, thus, the thermal stresses generated in the fuel plate on reactor shutdown. Post-irradiation measurement of residual stress, combined with fuel-performance modeling, provides a tool to gauge the effects of creep on swelling and evolution of stresses during irradiation, and shutdown-induced stresses. 


\section{FUEL QUALIFICATION AND DEMONSTRATION TESTING}

Figure 5 shows the current GTRI-USHPRR Road Map for the schedule of tests to collect data needed for the qualification of the base fuel. The purpose of each of these tests and the data provided for qualification are described below.

\subsection{Basic Objectives for Testing to Support Fuel Qualification for NRC Reactors}

The basic objectives for irradiation tests that support qualification of a fuel for NRC-regulated reactors are listed below. The test program was established based on historical precedent and previously demonstrated performance of U-Mo monolithic fuel to high burnup. Each test has a primary function that is not replicated elsewhere. Additional testing is required for ATR (see Section 5) and HFIR (see Section 6) because of high power density, surface-heat-flux requirements, and the complex fuel design required for HFIR.

- Data from the MP-1 test will be used to select the fuel plate fabrication process to be qualified. The MP-1 test will demonstrate that:

a. The selected fuel and fabrication processes are capable of meeting the requirements for base-fuel USHPRR reactor conversion

b. The selected fuel has a high probability of extension for use in ATR and HFIR.

NOTE: The statistical confidence in performance limits will be low at this point in the program because of the limited number of plates fabricated using each candidate process that will be tested in $M P-1$.

- MP-2 will collect additional data and improve statistical understanding of response variables for the fuel fabrication process selected as a result of the MP-1 test. The MP-2 test includes:
a. Mini-plates that represent pertinent features related to fuel performance phenomena for the three NRC-regulated USHPRR conversion element designs will be tested
b. A sufficient number of fuel plates to provide reasonable confidence that fuel-performance requirements continue to be met for the selected fuel fabrication process.

- The FSP-1 campaign will collect data to verify that, when scaled to geometries representative of fullsize conversion fuel plates, the selected fuel meets all fuel-performance requirements for conversion. The FSP-1 test:
a. Provides confidence in fuel performance at NRC USHPRR full-scale
b. Provides full-size plates for blister testing
c. Provides a predecessor to the ET-1 full-element test in ATR driver-fuel positions.

- ET-1 is the final demonstration of the fuel in a nominal prototypic geometry prior to submittal of the Base Fuel Qualification Report to NRC. The ET-1 test:
a. Irradiates 2 prototype ATR LEU conversion fuel elements in a specific ATR driver-fuel position under limited power testing conditions to conversion element fission density targets
b. Demonstrates repeatable fuel performance for a moderate number of fuel plates (38) fabricated using a commercial process on the pilot scale.
c. Provides full-size plates for blister testing
d. Provides a predecessor to the ET-2 test for irradiation of multiple ATR conversion elements in ATR driver-fuel positions.




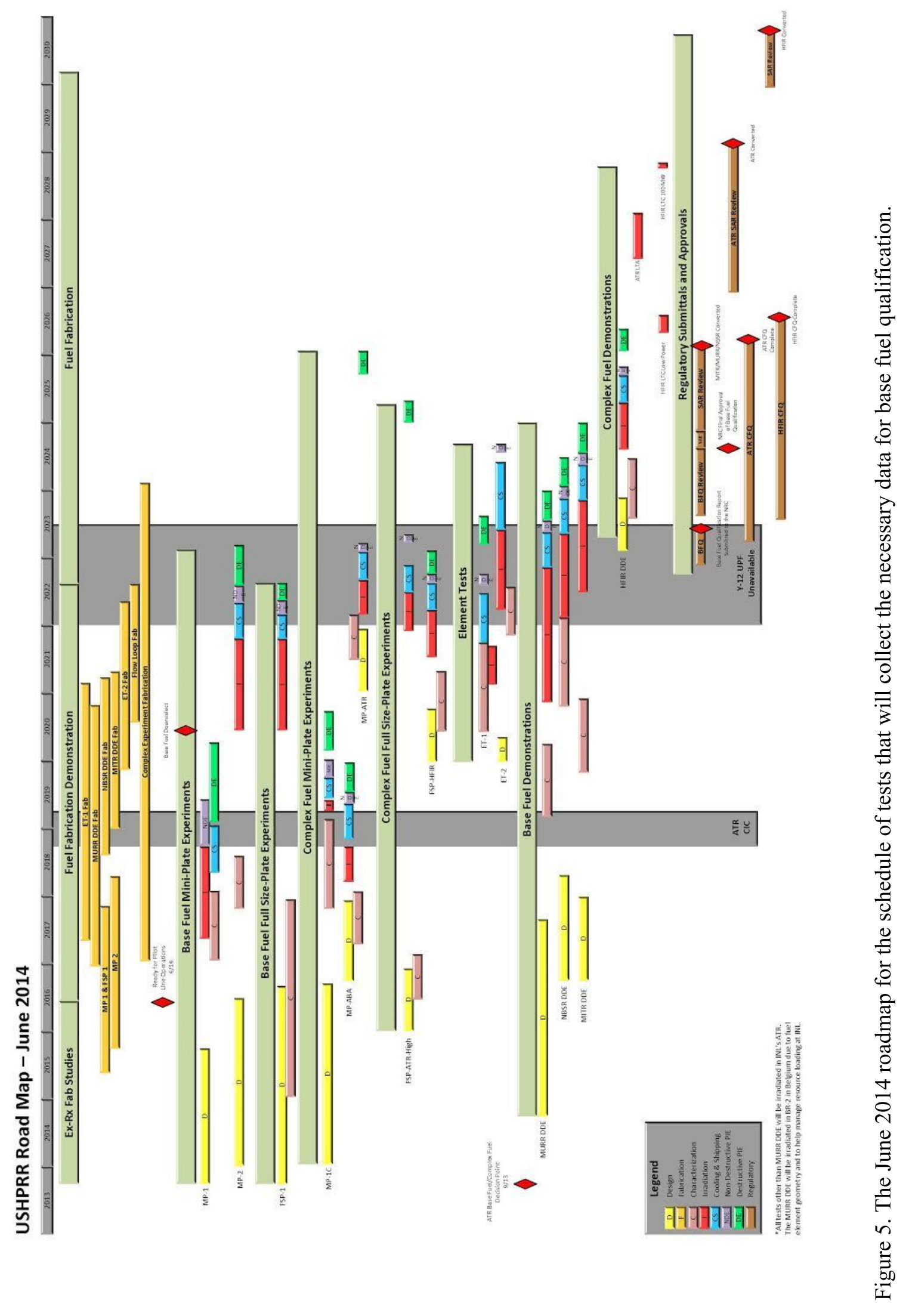


- ET-2 will provide statistically significant demonstration of representative fuel design from production scale supplier prior to NRC reactors conversions. The ET-2 test:

a. Irradiates 10 prototype ATR LEU conversion fuel elements in any ATR driver fuel position under operating conditions typical of normal-power ATR cycles. Normal-power ATR cycles are characterized by operation of 2 primary coolant pumps only and do not include power-actuated lobe mechanism (PALM) cycles.

b. Demonstrates repeatable fuel performance for a large number of fuel plates (190) fabricated using a commercial process on the pilot scale

c. Provides a predecessor to testing ATR conversion elements under ATR high-power operating conditions. High-power ATR cycles are characterized by operation of 3 primary coolant pumps and are often referred to as PALM cycles.

d. Provides additional full-size plates for blister testing to improve response statistics.

- DDE tests provide verification that prototypic NRC reactor fuel elements, containing conversion element fuel-plate geometries and irradiated under conditions prototypic of reactors to be converted meet conversion fuel-performance requirements. The DDE tests are the final irradiation demonstration prior to reactor conversion of the NRC reactors.

\subsection{Plate Testing}

\subsubsection{MP-1}

The objective of the MP-1 test is to provide sufficient information on fuel performance, in conjunction with fabrication studies, to select an LEU fuel design that meets HPRR fuel performance and commercial fabrication requirements. Test design and implementation are guided by a chartered crosspillar working group. The test will be designed to optimize the reliability and statistical significance of decisions made using MP-1 results, while allowing sufficient test space to test promising fabrication variants. MP-1 will provide enough test plates adequate to generate blister threshold test results. MP-1 data will be critical to development and benchmarking of the U-Mo monolithic fuel performance code.

The determination to stop testing at any point throughout the process (i.e., exit criteria) will be defined by the working group in the test plans.

The MP-1 test will focus on demonstrating the irradiation performance of fuel plates fabricated using commercially viable processes. The three principal fuel performance metrics are in-reactor dimensional stability (as measured by post-irradiation inspection of plate swelling), structural integrity (no fissionproduct release), and post-irradiation blister-threshold temperature. A small number of specimens fabricated using the previously tested laboratory-scale fabrication processes will be included in the test matrix to provide a link back to known irradiation behavior, for comparison with the new fabrication processes.

In order to demonstrate these requirements, post-irradiation examination includes ${ }^{17}$ :

- Visual examination

- Profiling of dimensional characteristics, including point-by-point surface contours and bulk volume increase in order to quantify the magnitude of specimen swelling

- Measuring thickness of the surface oxide layer

- Determining burnup distribution within the fuel meat

- Establishing mechanical integrity of entire meat region to establish the effect, if any, of fuel cracking and/or relocation 
- Measuring the post-irradiation residual-stress state

- Blister-threshold-temperature testing

- Burnup analysis

- Meat-cladding and cladding-cladding bonding interfaces tests and examinations to quantify their bond strength

- Examining specimen cross-sections at the microscopic scale with regard to the evolution of the microstructural features under irradiation, including material degradation due to fission/fluence damage, irradiation creep of materials, cross-sectional swelling profiles, and fission-gas-bubble morphology

- Post-irradiation measurement of mechanical properties

\subsubsection{FSP-1}

The FSP-1 test demonstrates suitable irradiation performance for the selected monolithic fuel design on fuel plates at the size scale required for USHPRR reactor conversion. Fuel selection made on the basis of the MP-1 test determines the fuel-fabrication process to be irradiation tested in the FSP-1 test. FSP plates are fabricated at the same time as MP-1 plates. This test provides an important link between the generic process selection leading to base fuel design selection, and the later geometry-specific qualification of fuel performed during demonstration of full-fuel-element performance (ET and DDE tests). The FSP-1 test precedes the ET-1 test elements for insertion in ATR driver fuel position(s). For this reason, FSP-1 must also address ATR normal-power cycle irradiation conditions and be characterized after irradiation in the ATR canal by ultrasonic scanning to expedite insertion of ET -1 . The test will focus on both steady-state irradiation performance and determination of plate-size effects on the blister-threshold temperature. In order to provide adequate data for blister threshold testing, the FSP-1 test train will require the ability to irradiate up to six test plates, will be designed as a hybrid system that can irradiate both full-size plates and smaller-scale test plates, or will conduct multiple irradiation insertions. Sections of FSP-1 test plates may also be used for fission-product-release measurements.

The FSP-1 test demonstrates requirements for mechanical integrity during normal and off-normal operating conditions, geometric stability, stable and predictable behavior on scale-up, demonstrates inputs into establishing the reactor mission envelope for NRC reactors, and also verifies that design requirements have been met for fuel plates by determining the behavior of full-size monolithic fuel plates under irradiation conditions representative of the USNRC licensed reactors that are candidates for conversion. Behavior during off-normal operating conditions is demonstrated through blister threshold testing and fission-product-release measurements.

In order to demonstrate these requirements, PIE includes $[28]^{25}$ :

- Ultrasonic scanning in the ATR canal

- Visual examination

- Profiling of dimensional characteristics, including point-by-point surface contours and bulk measurement of volume increase in order to quantify the magnitude of specimen swelling

- Measuring the thickness of the surface oxide layer

- Determining burnup distribution within the fuel meat

- Establishing mechanical integrity of entire meat region to establish the effect, if any, of fuel cracking and/or relocation

- Measuring the post-irradiation residual stress state

- Blister-threshold-temperature testing 
- Burnup analysis

- Meat-cladding and cladding-cladding bonding interfaces tests and examinations to quantify their bond strength

- Examining specimen cross-sections at the microscopic scale with regard to the evolution of the microstructural features under irradiation, including material degradation due to fission/fluence damage, irradiation creep of materials, cross-sectional swelling profiles, and fission-gas-bubble morphology

- Post irradiation measurement of mechanical properties

\subsubsection{MP-2}

The MP-2 test establishes acceptable normal and off-normal fuel performance for the range of operating conditions (from low to intermediate power density), for the geometrical plate designs used by the NRC licensed USHPRRs. Sufficient test plates are irradiated after fabrication by the single process selected as the outcome of MP-1 to establish that fuel performance is repeatable and to generate additional data on blister-threshold temperature as a function of burnup necessary to verify that fuelperformance requirements are met within the operating envelope defined the NRC USHPRRs.

The MP-2 test demonstrates mechanical integrity during normal and off-normal operating conditions, stable and predictable behavior, verifies fuel performance in the established reactor mission envelope, and verifies that design requirements have been met by determining the behavior of monolithic fuel miniplates plates under the range of heat flux, temperature, and burnup that bound NRC reactors. The MP -2 test verifies adequate fuel blister-threshold temperature performance for the selected fabrication process for representative NRC-reactor fuel-plate geometries. The MP-2 test is used as an initial demonstration of the performance of fuel fabricated with test plate designs specific to reactor conversion element designs, including thick fuel and thin cladding.

In order to demonstrate these requirements, post-irradiation examination includes ${ }^{19}$ :

- Visual examination

- Profiling of dimensional characteristics, including point-by-point surface contours and bulk measurement volume increase in order to quantify the magnitude of specimen swelling

- Measuring the thickness of the surface oxide layer

- Determining burnup distribution within the fuel meat

- Establishing mechanical integrity of entire meat region to establish the effect, if any, of fuel cracking and/or relocation

- Measuring the post-irradiation residual stress state

- Blister threshold temperature testing

- Burnup analysis

- Meat-cladding and cladding-cladding bonding interfaces tests and examinations to quantify their bond strength

- Examining specimen cross-sections at the microscopic scale with regard to the evolution of the microstructural features under irradiation, including material degradation due to fission/fluence damage, irradiation creep of materials, cross-sectional swelling profiles, and fission-gas-bubble morphology

- Post-irradiation measurement of mechanical properties 


\subsection{Fuel-element Tests}

\subsubsection{ET-1}

A final demonstration of the fuel in a nominally prototypic geometry is required prior to generic acceptance of base fuel for use in NRC USHPRRs. To accomplish this objective, two elements of ATRconversion-element design will be fabricated at a commercial vendor in accordance with the ATR Conversion Element Specification and ATR quality-assurance requirements. Irradiation of these elements in ATR will require an ATR SAR change (or SAR addendum). Once fabrication is complete, ATRC runs will be performed to determine the nuclear characteristics of the element. Each element will be irradiated in a driver core position for three to four normal-power ATR operating cycles with limited operating conditions. The elements may be inserted in alternating or consecutive cycles to meet ATR Operations requirements and to minimize the programmatic impact if one of the elements is damaged during handling or irradiation. Visual inspection and channel-gap measurements will be conducted between each irradiation cycle to confirm that the elements perform as expected. Irradiation of ET-1 elements will be terminated when the fission density reaches values representative of ATR-conversion fuel-element terminal burnup.

FD is responsible for the conduct of the ET-1 and ET-2 tests. RC (ATR conversion) ensures that the ATR SAR modifications and supporting safety analysis are adequate to support the tests. Because the test elements will be identical to ATR conversion elements, the development of the conversion fuel-element specification is funded by RC. The ATR-fuel Design Authority will approve the conversion-element fuel specification.

SAR addendums to be developed and implemented by RC include ATR, the fuel receipt facility, and the ATRC. Implementation requires various document modifications, training, and management and oversight readiness reviews.

In order to demonstrate these requirements, PIE includes ${ }^{19}$ :

- Channel-gap measurement between each irradiation cycle

- Visual examination of the fuel element before irradiation, between irradiation cycles, and after irradiation in the canal

- Fuel-element neutron tomography to verify channel gap

- Fuel-element dimensional inspection (bow, twist)

- Fuel-element gamma scanning

- Visual inspection of all fuel plates

- Dimensional measurement of thickness point-by-point on each plate in order to quantify the magnitude of specimen swelling on at least 7 fuel plates

- Axial gamma scanning of at least 7 fuel plates, including at least 2 plates at high resolution

- Radial gamma scanning of at least 2 fuel plates at high resolution

- Oxide-thickness measurements of at least seven plates

- Measurement of the thickness of the surface oxide layer on at least 7

- Optical metallography and microhardness testing of at least 2 plates

- Micro-hardness measurements of two to three plates

- Burnup analysis of at least 3 plates 
- Post-irradiation testing of mechanical properties

- Blister-threshold-temperature testing of approximately 19 plates.

\subsubsection{ET-2}

ET-2 will provide a large-scale demonstration of repeatable fabrication and irradiation performance for commercially fabricated U-Mo fuel. The demonstration will consist of ten elements (190 plates) irradiated in ATR driver-fuel positions at normal-power, non-PALM cycle conditions. The elements will be of ATR-conversion-element design, fabricated at a commercial vendor in accordance with the ATR Conversion Element Specification and ATR quality-assurance requirements. Current assumptions are for two sets of five elements to be inserted in the ATR, each for three to four cycles. The cycles are assumed to be staggered so that irradiation of the first set of five elements is completed after five normal reactor cycles, and the second set of five elements complete irradiation after between six and eight normal reactor cycles. Visual examinations and coolant-channel-gap measurements will be made between irradiation cycles to confirm that the elements perform as expected.

To meet objectives for qualification for both NRC and ATR fuel qualification, post-irradiation examination of the ET-2 elements will include ${ }^{19}$ :

- Channel-gap measurement between each irradiation cycle

- Visual examination of the fuel element before irradiation, between irradiation cycles, and after irradiation in the canal

- Fuel-element neutron tomography to verify channel gap

- Fuel-element dimensional inspection (bow, twist)

- Fuel-element gamma scanning

- Visual inspection of all fuel plates

- Dimensional measurement of thickness point-by-point on each plate in order to quantify the magnitude of specimen swelling on at least 7 fuel plates

- Axial gamma scanning of at least 7 fuel plates, including at least 2 plates at high resolution

- Radial gamma scanning of at least 2 fuel plates at high resolution

- Measuring of the thickness of the surface oxide layer on at least 7

- Optical metallography and micro-hardness testing of at least 2 plates

- Burnup analysis of at least 3 plates

- Post-irradiation testing of mechanical properties

- Blister-threshold-temperature testing of approximately $50 \%$ of the irradiated fuel plates. The number of plates to be blister tested will be determined based on the data scatter and required confidenceinterval band prior to testing.

Because the ATR-conversion fuel-element design will be used for the ET-2 demonstration irradiation the fuel technical basis (effectively the detailed ATR fuel-qualification case) that supports the ATR SAR addendum developed and implemented for ET-1 at ATR is valid for ET-2. The ATR fuel receipt and storage facility, and the ATRC SAR addendums for the ET-1 irradiation are applicable to the ET-2 irradiation test. Also, implementation, training, transport methods, reactor- and canal-handling tools, channel-gap probe fixtures, and hot-cell readiness activities are all directly applicable to ET-2. These assumptions are not valid if ET-1 and ET-2 element-designs differ. 


\subsection{DDEs}

A final series of irradiations for full-size plates with final geometries in a multi-plate configuration is needed to provide a demonstration of the final design and fabrication process. DDE tests demonstrate performance of reactor-specific fuel designs through irradiation of either full reactor elements or prototypic element assemblies for each of the NRC-regulated reactors. DDEs are designed to be prototypic of USHPRR conversion fuel elements and are irradiated under conditions designed to be as prototypic of actual reactor operating conditions as possible. Approval of the reactor-specific DDE testelement specification and irradiation test plan by each of the NRC-regulated USHPRRs is required prior to irradiation.

While completely prototypic conditions may not be achievable in any reactor except the one for which the LEU conversion element is designed, the DDE irradiations are intended to accomplish several critical functions:

- Confirm performance under prototypic irradiation parameters (e.g., heat flux, volumetric power, fission density)

- Confirm resistance to potential failure modes for reactor-specific plate and element designs at full scale

- Demonstrate fabrication by producing the plates/elements as demonstration products to the requirements of a conversion element specification

- Provide confidence in the LEU fuel designs prior to conversion.

Concurrent with the DDEs, the ET-2 demonstration and hydraulic testing of actual conversion elements in a flow loop will be conducted. After completion of this testing, and assuming completion of analyses required for reactor conversion, the USHPRR Conversion Program anticipates NRC approval for LEU conversion of USHPRR base fuel reactors. After successful GTRI/USHPRR base fuel qualification, the ownership of the then current set of fuel specifications will transition to each USHPRR.

PIE for design demonstration elements is confirmatory in nature. The scope of the PIE ensures that the fuel, when irradiated in reactor-specific test-element configurations, continues to meet fuelperformance requirements for qualification. In order to demonstrate these requirements, PIE includes ${ }^{19}$ :

Profiling of dimensional characteristics including length, width, and point-by-point surface contours in order to quantify the magnitude of specimen swelling

- Channel-gap measurement between each irradiation cycle

- Visual examination of the fuel element before irradiation, between irradiation cycles, and after irradiation in the canal

- DDE dimensional inspection (bow, twist)

- DDE gamma scan

- Visual inspection of all fuel plates

- Dimensional measurement of thickness point-by-point on each plate in order to quantify the magnitude of specimen swelling on at least 2 fuel plates

- Axial gamma scanning of at least the 2 fuel plates with highest fission density

- Radial gamma scanning of at least the 2 fuel plates with highest fission density

- Measuring of the thickness of the surface oxide layer on at least 2 plates 
- Burnup analysis of at least 2 plates

- Blister-threshold-temperature testing of approximately $50 \%$ of irradiated plates 


\section{ADVANCED TEST REACTOR}

\subsection{Background Information}

The ATR research reactor located at Idaho National Laboratory (INL) is a loop reactor that uses 40 reconfigurable fuel elements, each consisting of 19 fuel plates. This reactor has previously used complex fuel designs, i.e., designs that incorporate burnable absorbers such as boron. However, recent analyses have shown that alternative fuel designs without burnable absorbers may be used, meaning that ATR can convert to LEU using the base-fuel design. ${ }^{7}$

This section pertains to additional testing and requirements for qualification of fuel for conversion of ATR, beyond the testing and requirements discussed in Sections 3 and 4 above. Because ATR will be converted using plates of base-fuel design, qualification builds upon the basis established for the NRC reactors. This occurs by acceptance by DOE through SAR updates once the base fuel is approved. Demonstration of the base fuel uses ATR conversion element designs during the ET -1 and ET -2 test programs. Extension of testing of mini-plates and full-size plates to envelope ATR fuel plate power density and heat flux requirements is required. Additional fission-product release measurements may also be required.

\subsection{ATR Description}

\subsubsection{Core Design}

The ATR is a pressurized-water test reactor that operates at low pressure and low temperature. It contains a beryllium reflector to help concentrate neutrons in the core, where they are needed for fuels and materials testing. ATR normally operates at approximately 100-120 MW total core power. ATR has a unique serpentine core which allows the reactor's corner lobes to be operated at different power levels, making it possible to conduct multiple simultaneous experiments under different testing conditions. For example, operation at high neutron flux $\left(4.4 \times 10^{14}\right.$ thermal and $2.2 \times 10^{14}$ fast neutrons $)$ is possible by operating a single or multiple lobes at nominal powers of up to $60 \mathrm{MW}$. Table 1 gives specifications from the design parameter for ATR fuels, and Figure 6 provides a top view of an ATR fuel element.

Table 1. ATR design parameters for current HEU core design.

\begin{tabular}{|l|l|}
\hline \multicolumn{1}{|c|}{ Design Parameters } & ATR \\
\hline General & 6061 aluminum \\
\hline Cladding material & 40 \\
\hline Number of fuel elements & 760 \\
\hline Total number of fuel plates & 0.278 \\
\hline Core volume (m $\left.{ }^{3}\right)$ & 35 to 43 \\
\hline Typical core loading (kg U-235) & 45 (effective full power) \\
\hline $\begin{array}{l}\text { Normal fuel element lifetime (days of } \\
\text { reactor operation) }\end{array}$ & \begin{tabular}{l|l} 
Core power \\
\hline Steady state thermal power (MW)
\end{tabular} \\
\hline Peak core linear power (kW/m) & 915 (with enveloping 70 MW lobe) \\
\hline $\begin{array}{l}\text { Average core specific power (MW/kg } \\
\text { U-235) }\end{array}$ & $5.82 \times 10^{9}$ (at 250 MW and 43.1 kg U-235) \\
\hline
\end{tabular}


Table 1. (continued).

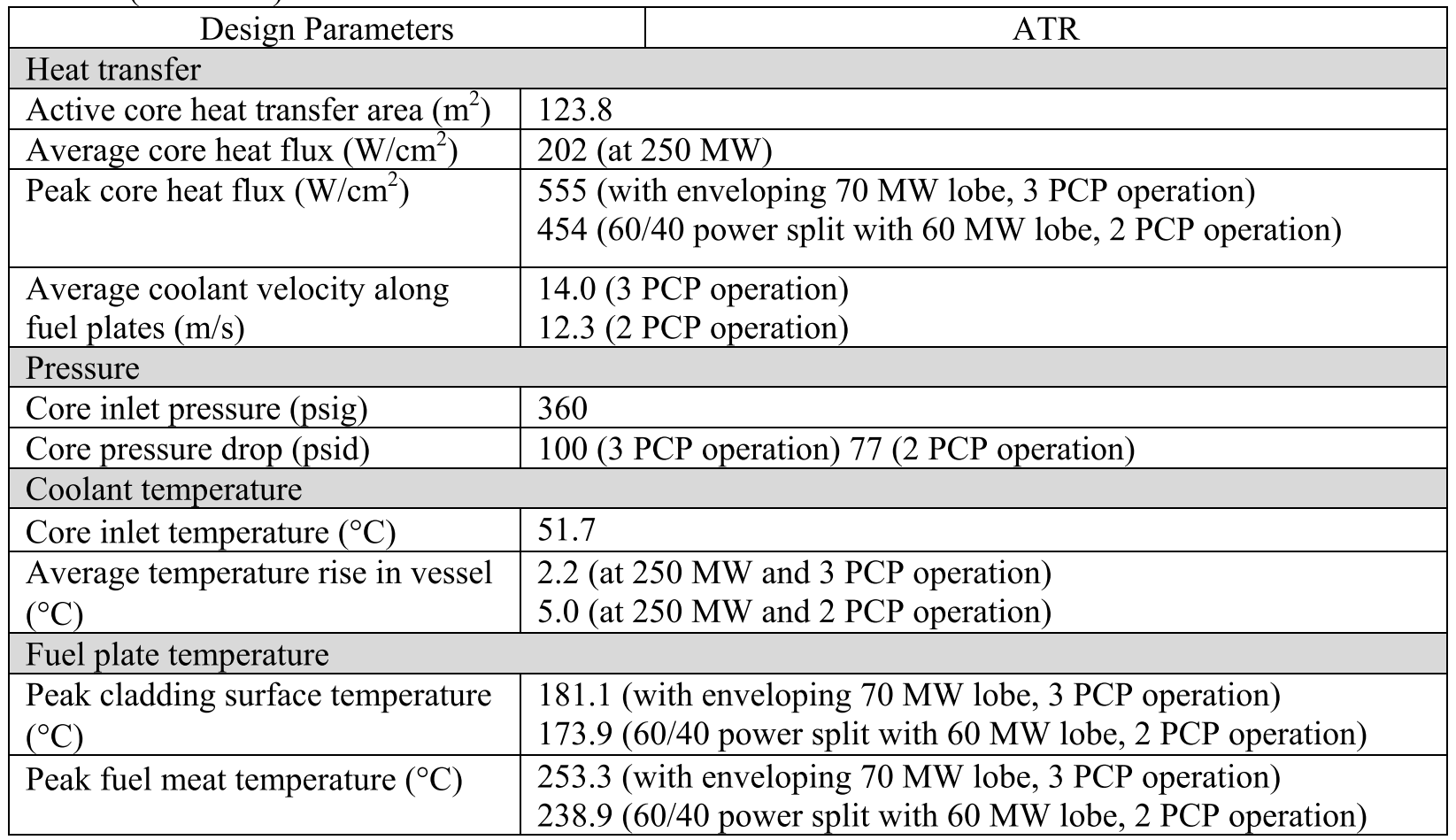

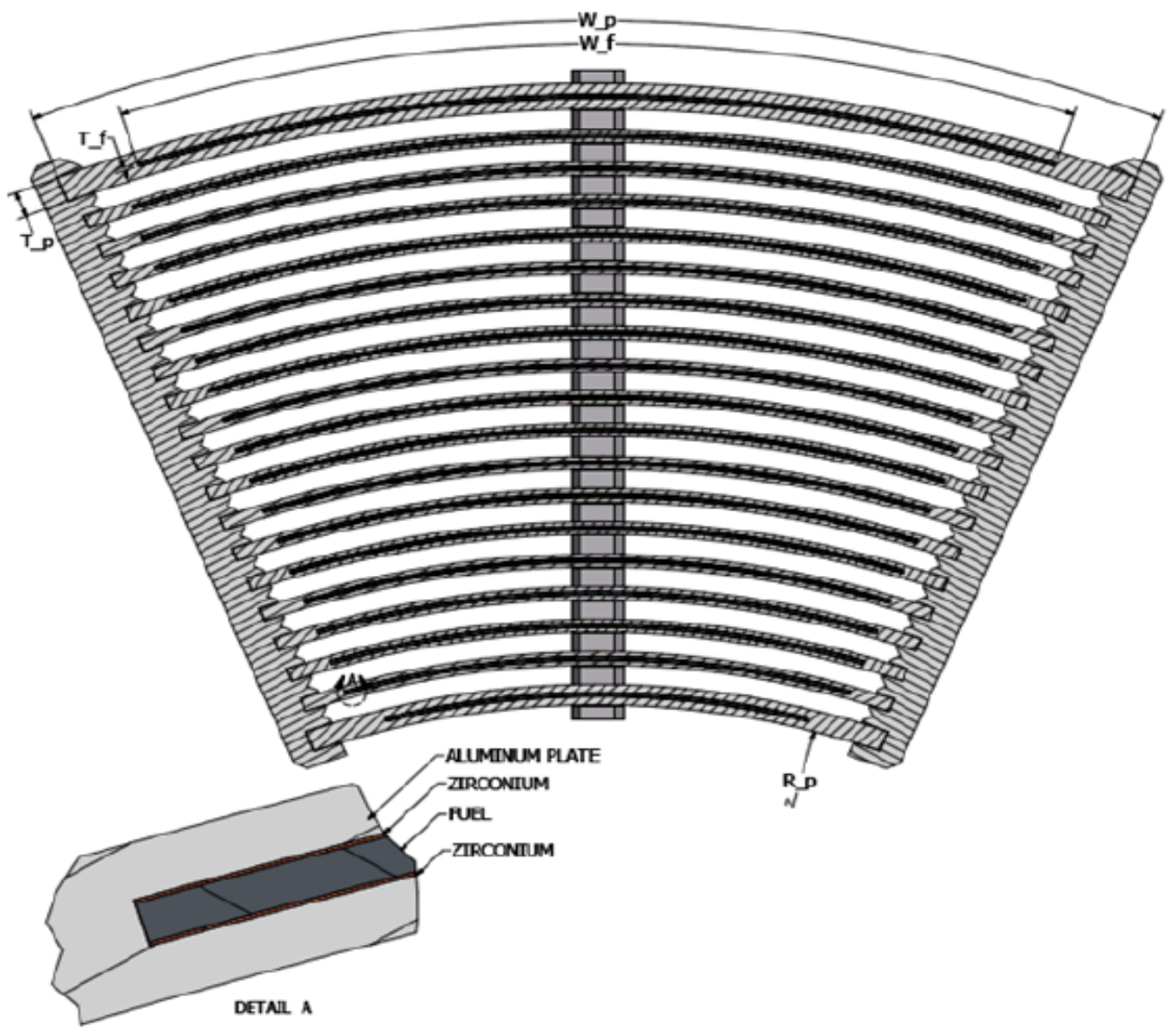

Figure 6. ATR fuel element. 


\subsection{ATR Reactor Conversion Schedule}

The USHPRR Roadmap gives a general schedule for the conversion of the ATR. ${ }^{12}$

\subsection{Fuel Product Specification}

Initially, ATR will rely upon the Fuel Product Specification for the generic base-fuel design under the responsibility of the DA (as described in Section 1.4 and Section 1.5), to develop fuel plate and fuel element preconceptual designs. Upon completion of ATR-conversion fuel-element conceptual design, ownership of the ATR LEU Fuel Element Specification will pass to the ATR fuel Design Authority. The eventual reactor-specific fuel specification for ATR, including the geometric configuration of the elements, shall satisfy all requirements included in an INL document technical and functional requirements document.

\subsection{Previous Qualification Efforts and Historical Precedence}

ATR fuel was originally manufactured by Oak Ridge National Laboratory as an aluminum-base dispersion containing $\mathrm{U}_{3} \mathrm{O}_{8}$ fuel, based on the operational characteristics of the reactor. Nineteen fuel plates were fabricated. ${ }^{26}$

The current ATR fuel design basis was determined by a 17 day, 4250 MWd cycle using powdered uranium-aluminide compounds in the fuel elements. Four fuel-element loadings, Core, 0, I, II, and III were used. PIE was performed on six fuel elements from these cores, one from Core I, 3 from Core II and 2 from Core III. ${ }^{27,28}$

Core I was used for intermediate power operation where fuel-element performance was evaluated under a number of contrived thermal-hydraulic conditions. The element from Core I had been used in an experiment designed to determine the rate at which corrosion-product oxide builds up on the heat transfer surfaces of the fuel plates under maximum nominal heat-flux conditions.

Core II was used for high-power operations and balanced-power demonstrations. Two of the three elements that were examined were operated in peak power position for 35 full-power days. Core II utilized both $\mathrm{U}_{3} \mathrm{O}_{8}$ fuel plates as well as $\mathrm{UAl}_{\mathrm{x}}$ plates. Both of these fuel plates were operated at $250 \mathrm{MW}$ balanced tests. PIE was performed on each of the fuel plate types. The UAl $\mathrm{x}_{\mathrm{x}}$ powder plates outperformed and were more stable than the $\mathrm{U}_{3} \mathrm{O}_{8}$ plates. ${ }^{28}$

Core III was used during the operation of the reactor for 27 days at $250 \mathrm{MW}$, maintaining an unbalanced power division. During unbalanced power, $40 \mathrm{MW}$ of power were generated in two lobes of the reactor core, $60 \mathrm{MW}$ were generated in the other two lobes, and $50 \mathrm{MW}$ were generated in the center.

PIE examinations were conducted to 1) determine the distribution of fuel burnup in the plates of the elements, 2) assess the stability of the fuel elements under reactor operating conditions, 3) compare the performance of full-size commercially produced fuel elements with that projected from mini-plate testing, and 4) determine, if possible, the safe operating limits of the current fuel-element designs for the ATR. ${ }^{27,28}$

Results of PIE testing showed that in areas of peak burnup, the fuel plates were still within the preirradiation thickness tolerances. The $7 \% \Delta \mathrm{V} / \mathrm{V}$ limit on core swelling may have been exceeded in some parts of the plates; however, the blister tests indicated that this was acceptable. ${ }^{27,28}$

Metallography samples showed that the fuel was sound at both intermediate and high burnup levels. No cracking from excessive gas-bubble agglomeration or fuel-particle growth was observed. Oxide was present in two layers. The inner layer was typically $60 \%$ of the total thickness and was intermittently cracked. The $40 \%$ oxide outside layer was more porous and did not exhibit cracking. The oxide contained both bayerite and boehmite. Blistering during the blister-anneal tests showed that cracks formed simultaneously throughout the core at temperatures where the aluminum matrix would have very little 
strength, suggesting that the pressure of the fission gas collected in the recoil zones could not be restrained by the aluminum matrix at the high temperature. ${ }^{27,28}$ Nothing was found in the metallography to suggest that the uranium-aluminide fuel had reached its limitation.

An additional test of the INC-16-1 sample train in the Engineering Test Reactor (ETR) was completed for a total of 18,667 MWd. At the end of 9,343 MWd, tiers 2 and 4 were interchanged in order to increase the burnup of the ATR 7F high-loaded fuels. Two sample fuel plates, one ATR regular and one ATR 7F high, were removed from the reactor at this point, having reached calculated peak burnups of $1.8 \times 10^{21}$ fissions $/ \mathrm{cm}^{3}$. Swelling at these higher burnup levels is in the thickness direction, rather than in the plane of the plate, which is consistent with the growth stress analysis performed. Gas-bubble agglomeration was beginning to occur in fuel particles with the highest fission densities; however, the plates were stable, as shown by immersion-density and blister testing. ${ }^{27}$

Experiments were performed to determine whether the necessary operating temperatures and burnups higher than $1.8 \times 10^{21}$ fissions $/ \mathrm{cm}^{3}$ could be achieved. INC-16-2 tests comprised nine sample fuel plates covering the range of ATR 7F fuel compositions irradiated in the ETR for 55,612 MWd. The fuel plates were encapsulated in sodium in a double-walled stainless steel capsule. Results showed the fuel to be typical of irradiated uranium-aluminide fuels; swelling was no more than theoretically predicted, and the fuel had excellent blister resistance. The fission densities of $2.88 \times 10^{21}$ fissions $/ \mathrm{cm}^{3}$ were reached. Based on the results of this test, the fission-density operating limits for ATR fuel could safely be increased to $2 \sigma$ levels of $2.6 \times 10^{21}$ fissions $/ \mathrm{cm}^{3}$ for $7 \mathrm{~F}$ high loads. ${ }^{29}$

\subsection{ATR-specific Fuel Requirements}

The ATR is designed so that its components meet the following safety and performance criteria:

- The mechanical design of the reactor-core components and their physical arrangement, together with corrective actions of the reactor-control and protective systems (when applicable) ensure that the ATR plant-protection criteria - located in SAR-153, Chapter 15, "Accident Analyses" - are met.

- The fuel elements are designed to withstand various loads induced during handling and reactor operations

- The reactor core and reflector are designed to accommodate movement of outer-shim control cylinder, neck-shim rods, regulating rods, and safety rods in order to provide the required reactivity control for power operations and outage conditions

- The reactor vessel and internals, reactivity in conjunction with the fuel elements, control components, and reflector blocks direct reactor coolant through the core.

The U-10Mo fuel has minimal effect on reactivity control systems, reactor instrumentation, and power oscillations. The effect of Doppler broadening will be more pronounced because of the muchhigher concentration of U-238 in the fuel. The enhanced Doppler-broadening effect will be localized and will have a small positive effect on fuel zone moderator/coolant temperature reactivity coefficients, but it is considered insignificant. There will be an increased weight on the ATR fuel-storage and grid racks. The ATR fuel elements are safety-related components; however, the physical geometry with LEU fuel will remain the same as currently used. The fuel-element cladding is required to exceed a minimum thickness to retain fission products, which can be met by a HIP-bonding process for LEU fuel, coupled with the presence of the Zr diffusion barrier. SPC-1635, "Specification for Low Enriched Uranium Monolithic Fuel Plates," provides the fuel specifications of the LEU fuel. ${ }^{30}$

Specific functional and performance requirements for the U-Mo demonstration fuel elements are defined in Reference ${ }^{31}$ and include:

- Fuel elements shall contain the fission products that are produced by the fission process

- Fuel elements shall reject heat flux sufficient to prevent burnout during steady-state operation 
- Fuel elements shall withstand short-term upset conditions without any fission-product release

- Fuel elements shall ensure that localized boiling flow instability does not occur during normal operation

- Fuel elements shall be designed to minimize cladding corrosion during operation

- Fuel elements shall be designed to maintain negative temperature and void coefficients of reactivity during operation

- Maximum fuel-element surface temperature shall be less than $20^{\circ} \mathrm{F}$ above saturation temperature

- Maximum fuel-element surface temperature during operation shall not exceed the temperature which causes excessive corrosion and oxide-film buildup

- Power level causing steady-state burnout in the U-Mo demonstration fuel elements shall be at least 1.4 times the rated power

- The total core design shall be capable of withstanding energy release of $100 \mathrm{MW} / \mathrm{sec}$ during the shutdown transient period without melting the U-Mo demonstration fuel elements

- Minimum Reynolds number in the fuel element shall be above the critical region during operation

- Fuel element maximum surface temperature, not including hot channel or hot spot factors, shall be limited to two standard deviations less than the surface temperatures at which nucleate boiling will commence

- U-Mo demonstration fuel elements, in conjunction with the ATR Mark VII fuel elements, shall provide neutron fluxes for experimental positions inside and outside the core.

In addition, the current ATR safety analysis requirements are: ${ }^{7}$

- An operational cycle length of 56 days at $120 \mathrm{MW}$

- Fast-to-thermal neutron flux ratio within $5 \%$ of current values in a pressurized-water loop test

- Greater than $4.8 \times 10^{14}$ fissions/sec/gram U-235 in a specimen with $1 \mathrm{~g} \mathrm{U-235/linear} \mathrm{inch} \mathrm{in} \mathrm{a}$ standard in-pile tube operating at $60 \mathrm{MW}$

- Three-quarters lobe power split with south corner lobes operating at three times the lobe power of the northern lobes

- Gamma-to-neutron flux ratio within $+10 \% /-0 \%$ of current values

- Maintenance of current core geometry

In addition, the ATR safety analysis requirements are 7:

- Fuel expansion (strain limit $0.6 \%$ )

- Loss-of-coolant-accident performance

- Reactivity-insertion-accident performance

- Departure from nucleate boiling

- Temperature reactivity (negative temperature coefficient)

- Prompt criticality period (prompt neutron generation time and life time)

- Hold down reactivity margin (min value: $6.7 \$$ )

- Shutdown reactivity margin (min worth of four/five least reactive SRs: $5.8 \$ \mathrm{w} / 3$ primary coolant pumps and $6.4 \$$ with 2 primary coolant pumps 